REVISTA DE DERECHO UNED, NÚM. 27, 2021

\title{
¿SEGUIRÁ SIENDO NECESARIO EL CONSENTIMIENTO DEL USUARIO PARA LOS COOKIES DE PUBLICIDAD COMPORTAMENTAL EN LÍNEA?
}

\author{
WILL USER CONSENT CONTINUE BEING NECESSARY FOR \\ ONLINE BEHAVIOURAL ADVERTISING COOKIES?
}

María del Rosario GutiérRez Palacios

Alumna de Doctorado en Unión Europea de la UNED.

\begin{abstract}
Sumario: I. Introducción. II. Cookies y publicidad comportamental en línea: concepto y tipología. III. Evolución del marco jurídico: sistemas opt-in y opt-out. III.A. Adopción del sistema opt-in ante el uso de cookies de publicidad comportamental. III.B. Relación entra la Directiva 2002/58/CE y la normativa sobre protección de datos personales. IV. Aplicación del artículo 5.3 de la Directiva 2002/58/CE. IV.A. Cookies sujetos a los requisitos de información y consentimiento previo. $I V . B$. Requisitos de validez del consentimiento para cookies de publicidad comportamental. V. Avisos de cookies. VI.A. Mecanismos de aceptación previa consistentes con un sistema opt-in. VI.B. Mecanismos que no constituyen un verdadero sistema opt-in. VI. Revisión de la Directiva 2002/58/CE y propuesta de un nuevo Reglamento. VI.A. Revisión de la Directiva 2002/58/CE. VI.B. Jurisprudencia del Tribunal de Justicia de la UE. VII. Propuesta de Reglamento: ePrivacy Regulation. VIII. El consentimiento para cookies en la Propuesta ePrivacy Regulation. VIII.A. Refuerzo moderado de la privacidad. IX. Conclusiones.
\end{abstract}

Resumen: El régimen actual de protección frente a la publicidad comportamental en línea que regula la instalación de cookies no resulta todo lo efectivo que debiera. Los cookies se siguen instalando 
en los terminales de los usuarios de Internet, en ocasiones sin su consentimiento. En muchos casos éstos desconocen qué son y qué finalidad persiguen. A la vez, multitud de páginas web siguen utilizando avisos de cookies que no se ajustan a la normativa. Hay un régimen que viene a futuro que está llamado a sustituir al actual. El presente artículo pretende exponer las razones que han motivado la evolución normativa, el régimen actual, y analizar si la propuesta de Reglamento va a dar una respuesta a los cookies. Si estamos volviendo a un sistema de consentimiento a ciegas o a uno en el que no resulte necesario pedir el consentimiento y por tanto si nos encontraremos ante a un sistema opt-in u opt-out.

Palabras clave: publicidad comportamental, cookies, consentimiento, datos personales, opt-in, opt-out.

Abstract: The present protection regime regarding online behavioural advertising that governs the installation of cookies is not as effective as it should be. Cookies continue being installed on Internet users' computers sometimes without their consent, and many of them are unaware of what cookies are and their purposes. At the same time there are web pages that still provide cookie notices which do not comply with the legal framework. This article aims at explaining the reasons that have caused the evolution of the existing regulation and analyse if the future regulation will provide a solution to cookies. If we are on a path back towards a blind consent system or if it will no longer be necessary to obtain the user's consent, and hence if we will be faced with an opt-in or an opt-out system.

Key words: behavioural advertising, cookies, consent, personal data, opt-in, opt-out.

Recepción original: 15-10-2020

Aceptación original: 18-12-2020

\section{INTRODUCCIÓN}

Actualmente una cantidad considerable de comercio electrónico es provocado por la publicidad que aparece en las diferentes páginas web por las que navegamos. En muchas ocasiones, los anuncios carecen de interés, si bien en otras coinciden con contenidos, productos, servicios que hemos consultado con anterioridad. Los segundos responden al diseño de una publicidad individualizada que se produce precisamente debido al empleo de archivos informáticos o cookies. Esta materia no es nueva, pues se lleva tratando específica- 
mente desde principios de este siglo. Ésta se ha ido poco a poco desarrollando en un ambiente de convergencia entre las regulaciones de los sectores que concurren en el mundo o mercado digital como son el de servicios de la sociedad de la información, y el de las comunicaciones electrónicas. La normativa por la que se rige la instalación de cookies ha evolucionado desde un sistema opt-out hacia un sistema opt-in. Este sistema, ha demostrado ser insuficiente para proteger a los usuarios frente a posibles injerencias en la esfera de su privacidad.

Fruto de la globalización de internet y el avance de las tecnologías, en la actualidad los cookies se han convertido en una herramienta fundamental para ofrecer este tipo de publicidad como estrategia de mercado para fomentar el comercio electrónico. La aparición de avisos de cookies en páginas web que anuncian su inminente instalación o que piden nuestro consentimiento para instalarlos se ha extendido de forma abrumadora en la última década.

La información a la que acceden, almacenan o recuperan los cookies de publicidad comportamental, se traduce en datos referidos a los gustos que expresa el usuario a través de su comportamiento a lo largo de sus sesiones de navegación por internet. Parte de estos datos corresponden a información acerca de los contenidos que se visitan. A modo de ejemplo, si se ha consultado información acerca de precios de vuelos a diferentes destinos, los datos permitirán, una vez tratados, que el usuario de internet vea en sucesivas sesiones de navegación anuncios relacionados con las búsquedas anteriores, lo cual se traduce en publicidad comportamental en línea.

Los distintos avisos de instalación de cookies que existen actualmente constituyen mecanismos destinados a dar cumplimiento, al régimen jurídico por el que se rigen. Están llamados a proponer soluciones basadas un sistema opt-in que exige que el usuario preste su consentimiento a través de una acción expresa previa a la instalación de los cookies. Sin embargo aun hoy conviven con avisos que todavía responden a un opt-out que se refieren a la oportunidad de oponerse $^{1}$ en un momento posterior a su instalación sin que resulte necesario contar con el consentimiento del usuario.

La evolución de este sistema que se apoyó inicialmente en un sistema opt-out para dar paso a un opt-in, se ha caracterizado por una falta de estabilidad, fruto de la interpretación de la norma eu-

${ }^{1}$ KOSTA, E., "Construing the Meaning of Opt-Out-An Analysis of the European, UK and German Data Protection Legislation”, Eur. Data Prot. L. Rev., 1, 16, 2015, pág. 3. 
ropea en los EEMMs. Su evolución se ha forjado en base a las diferentes fases que han ido regulando los sectores del mercado digital, a saber, el de las telecomunicaciones, los medios de comunicación y las tecnologías de la información ${ }^{2}$, en la UE. La regulación de los cookies comienza en un momento en el que los sectores de las telecomunicaciones y sociedad de la información, están regulados con cierta distancia. Por eso es importante tratar sus antecedentes y cómo ha sido su evolución que se produce por dos razones, no sólo porque fruto de la convergencia tecnológica ${ }^{3}$ hay un entrecruzamiento de estos dos sectores, sino porque los cookies también producen convergencia entre ambos, como se está viendo y vamos a demostrar. La normativa inicialmente basada en la publicidad no deseada, en ambos sectores, nos daba a elegir, en algunos casos, entre los sistemas optin y opt-out. Ésta se ha ido modulando por las distintas normas europeas en un intento por lograr el equilibrio entre los intereses del mercado y el derecho a la privacidad, lo que ha dado lugar a la regulación de cookies como una categoría específica.

La normativa relativa a la privacidad y las comunicaciones electrónicas, y al comercio electrónico, han sido las encargadas de regular la actividad en los sectores de las telecomunicaciones y la sociedad de la información respectivamente, quedando íntimamente ligadas a las obligaciones establecidas en la normativa sobre la protección de las personas físicas en lo que respecta al tratamiento de datos personales. La interrelación y convergencia de los sectores del mercado digital, que se evidencia de las sucesivas transposiciones a nuestro ordenamiento jurídico, ha supuesto, una serie de "cruces" entre los sectores de las telecomunicaciones y la sociedad de información al converger en determinados momentos en el régimen que inicialmente regulaba las comunicaciones electrónicas que, a su vez,

2 Vid. Bendito Cañizares, M. T., "La autorregulación en el Reglamento General de Protección de Datos como solución frente al mercado digital fragmentado: el menor y los Registros." Revista Crítica de Derecho Inmobiliario 94, n 770, 2018, págs. 3119-3172, págs. 3221-3122.

3 Si originariamente cada red era diseñada exclusivamente para soportar un determinado servicio de telecomunicaciones o audiovisual, la evolución de las mismas ha hecho posible que diferentes servicios (por ejemplo, el servicio telefónico y el acceso a internet) puedan ser soportados por una misma red, fenómeno que para el que se ha acuñado el término "convergencia y que ha evolucionado para hacer referencia no sólo a la Red, sino también a otros niveles como el de la tecnología, los terminales, las aplicaciones, los servicios e incluso la propia regulación, siendo numerosas las expresiones de este fenómeno. CASTILLEJO GARCIA, Á., "La regulación de los contenidos audiovisuales", págs. 23-34, en LLANEZA, P. (coord.) TELOS 85: Los derechos fundamentales en Internet, Fundación telefónica, diciembre a octubre 2010, pág. 27. 
pasó a regular instalación de cookies en los terminales de los usuarios de internet.

En este artículo explicaremos qué son los cookies y su relación con la publicidad comportamental. Resumimos la evolución de la normativa en los diferentes sectores hasta alcanzar el régimen actual de cookies. Expondremos el grado de cumplimiento que se desprende, entre otros, de la jurisprudencia del Tribunal de Justicia de la Unión Europea así como de los documentos que reclaman la actualización de la norma. Finalmente, analizaremos las disposiciones relativas a los cookies contenidas en el futuro "ePrivacy Regulation" llamado a sustituir a la regulación vigente contenida en la actual "Directiva sobre privacidad y comunicaciones electrónicas", eje central de la regulación es esta materia en un intento por determinar el nivel de protección que otorga.

\section{COOKIES Y PUBLICIDAD COMPORTAMENTAL EN LÍNEA: CONCEPTO Y TIPOLOGIA}

La primera referencia a los cookies en la normativa europea la encontramos en el CDO 25 de la Directiva 2002/58/CE ${ }^{4}$ que los denomina chivatos, una categoría de dispositivo contenida la clasificación que hace la misma Directiva en su CDO 24. Esta clasificación incluye también los denominados programas espía (spyware), web bugs, y los identificadores ocultos. A todos ellos les atribuye la capacidad de introducirse en el terminal del usuario sin su conocimiento, y tres características, las de acceder a información, archivar información oculta o rastrear las actividades del usuario. Si bien es cierto que en el mismo CDO 24 se determina que pueden suponer una grave intrusión en la intimidad de dichos usuarios, el CDO 25 establece que los chivatos o cookies pueden constituir un instrumento legítimo y de gran utilidad, distinguiendo entre tres finalidades claramente diferenciadas: cookies cuya finalidad es el análisis de la efectividad del diseño de sitio web, cookies destinados el análisis del diseño de la publicidad, y aquéllos de verificación de la identidad de un usuario.

Si bien inicialmente sencilla, esta distinción por finalidades ha supuesto la base de la regulación de los cookies, como se verá más adelante. En concreto, la proliferación en uso de cookies de análi-

4 Directiva 2002/58/CE del Parlamento Europeo y del Consejo, de 12 de julio de 2002, relativa al tratamiento de los datos personales y a la protección de la intimidad en el sector de las comunicaciones electrónicas (Directiva sobre la privacidad y las comunicaciones electrónicas) OJ L 201, 31.7.2002. 
sis de la efectividad de la publicidad de un sitio web, unido a los avances tecnológicos puso en evidencia su potencial y evidenció más tarde la existencia, de una nueva modalidad de publicidad que ha pasado a denominarse "publicidad comportamental en línea".

Conocida también por su terminología anglosajona como OBA (Online Behavioural Advertising), la publicidad comportamental en línea, fue definida institucionalmente por el Dictamen 2/2010 sobre publicidad comportamental en línea ${ }^{5}$ en adelante Dictamen 2/2010), del Grupo de Trabajo de Protección de Datos del art. 29 (en adelante GT29) como la publicidad basada en la observación continuada del comportamiento de los individuos. Esta definición si bien escueta, aporta las palabras clave, publicidad, observación, continuada y comportamiento, que nos permiten describirla en mayor detalle.

La publicidad comportamental busca estudiar las características del comportamiento de los usuarios a través de sus acciones (visitas repetidas a un sitio concreto, interacciones, palabras clave, producción de contenidos en línea, etc.), para desarrollar un perfil específico y proporcionar asi a los usuarios, anuncios a medida de los intereses inferidos de su comportamiento ${ }^{6}$. Cada vez que un usuario realiza alguna de estas acciones el cookie se encarga de recabar los datos correspondientes. Estos datos que corresponden al comportamiento del usuario pueden incluir las páginas web visitadas, artículos y vídeos a los que se accede, así como todas las búsquedas realizadas a través de un motor de búsqueda ${ }^{7}$.

El significado de publicidad comportamental que aporta La Guía $\mathrm{EASA}^{8}$ de buenas prácticas en publicidad comportamental online arroja luz sobre cómo se produce la observación continuada al incluir el factor temporal. Al indicar que la captación de información... so-

5 Dictamen 2/2010 sobre publicidad comportamental en línea, adoptado el 22 de junio de 2010. Grupo de trabajo de protección de datos del artículo 29. 00909/10/ ES, GT 171.

6 Dictamen 2/2010, pág. 5.

7 BOERMAN, S.C., KRUIKEMEIER, S. \& ZUIDERVEEN BORGESIUS F. J., "Online behavioural advertising: A literature review and research agenda." Journal of advertising 46, no. 3 (2017): 363-376, pág. 363. DOI: 10.1080/00913367.2017.1339368

8 La Guía EASA es un texto acordado por la industria y los organismos de autorregulación a nivel comunitario. Si bien no es formalmente vinculante, ofrece apoyo y asesoramiento a las organizaciones de autorregulación de EASA y a los miembros de industria, y pretende servir como medio para la adopción de medidas claras tanto a nivel nacional como europeo en torno a la práctica de la publicidad comportamental. Guía EASA de buenas prácticas en publicidad comportamental online de 13 de abril de 2011 (Traducción no oficial de AUTOCONTROL. Documento original: "EASA Best Practice Recommendation on Behavioural Advertising), pág. 7. 
bre el comportamiento de navegación en internet se produce a través del tiempo y a través de varios dominios web que no están bajo Control Común ${ }^{9}$, da a entender que se hace un seguimiento del comportamiento. El tiempo durante el que se recaban datos dependerá de la "vida" o duración del cookie, y determinará así el periodo de tiempo durante el cual se produce la observación continuada del comportamiento. La misma Guía, además, pone de relieve la existencia de un componente predictivo al indicar que su objetivo es utilizar dichos datos para predecir las preferencias o intereses del usuario y ofrecerle publicidad en ese dispositivo particular ${ }^{10} .$. puesto que el perfil, fruto del tratamiento de los datos permite predecir y con ello seleccionar los anuncios que corresponden a los intereses del usuario.

Este proceso complejo, que supone la intervención de diferentes actores $^{11}$, se materializa en el producto final, es decir los anuncios que verá el usuario. A ellos se refiere PÉREZ BÉS al definir la publicidad comportamental como aquella publicidad que se muestra durante una concreta navegación, por razón de la actividad online que se ha venido desarrollando durante un periodo de tiempo determinado, desde ese mismo navegador ${ }^{12}$. Si bien se basa en la definición del GT29, y pone el acento en la representación final de la publicidad, también destaca que el rastreo de la actividad tiene una duración determinada, y que se hace desde un mismo navegador. Lo último permite personalizar la publicidad porque la actividad se presume corresponde a un único usuario, y porque los datos obtenidos

9 El control común hace referencia a al control que ejerce una empresa matriz sobre los sitios web de forman parte de ese grupo, así como la entidades que hayan suscrito un acuerdo con la matriz que le permitan tratar los datos en su nombre de y con su aprobación. Guía EASA de buenas prácticas en publicidad comportamental online de 13 de abril de 2011 (Traducción no oficial de AUTOCONTROL. Documento original: "EASA Best Practice Recommendation on Behavioural Advertising), pág. 11.

${ }_{10}$ Guía EASA, pág. 12.

11 El Dictamen 2/2010 distingue entre editores, proveedores de redes de publicidad, y anunciantes y explica detalladamente el proceso que podemos resumir en los siguientes pasos. Los editores alquilan espacio en sus sitios de internet a las redes de publicidad para colocar anuncios. Para ello configuran sus sitios de modo que los buscadores de los usuarios sean direccionados automáticamente a la página web del proveedor de redes de publicidad. Éstos a su vez envían y colocan cookies que recuperan información almacenada en el terminal. La información o datos son tratados para crear un perfil que permite seleccionar y mostrar anuncios que responden al comportamiento de un usuario concreto. Finalmente, encontramos a los anunciantes, que son aquéllos cuyos anuncios aparecen en los sitios de los editores y que responden a los perfiles elaborados por los proveedores de publicidad. Dictamen 2/2010, págs. 5-13.

12 PÉREZ BES, F., La publicidad comportamental online, Editorial UOC, 2012, pág. 14 .

(C) UNED. Revista de Derecho UNED, núm. 27, 2021 
pueden corresponder a múltiples sesiones de navegación del usuario, lo que permite a su vez hacer un seguimiento de la actividad.

Puesto que la publicidad comportamental supone el tratamiento de datos recabados a lo largo de un periodo de tiempo y la elaboración de un perfil, nos centramos en los cookies que recaban o recuperan datos y que cumplen estas características y que en nuestra opinión coinciden con los cookies destinados al análisis del diseño de la publicidad enunciados en el CDO 25 de la Directiva 2002/58/CE.

Los cookies son en general, pequeños ficheros de texto que los sitios web instalan en el ordenador o dispositivo móvil de los usuarios que las visitan ${ }^{13}$ y han de entenderse como tecnologías basadas en el principio de almacenamiento y recuperación de la información en el terminal del usuario ${ }^{14}$. Las "Guías sobre el uso de las ${ }^{15}$ cookies" de la Agencia de la Española de protección de datos (en adelante, La Guía AEPD 13 o 19) recalcan que su finalidad es almacenar información y recuperar la información ya almacenada ${ }^{16}$. Si bien no mencionan la capacidad que tienen de acceder a la información, entendemos que ésta se presume por cuanto para recuperar información se ha de haber posibilitado el acceso a la misma tal y como señala el CDO 24 Directiva 2002/58/CE al indicar que "pueden introducirse en el terminal del usuario sin su conocimiento para acceder a la información...".

La tipología de cookies es muy extensa tal y como se desprende de la lectura de los Dictámenes del GT29. El Dictamen 2/2010 alude a los "cookies de rastreo" como técnicas para producir publicidad comportamental, a la vez que menciona diferentes tipos de cookies. Por su parte el Dictamen 4/2012 sobre la exención del requisito del consentimiento de cookies ${ }^{17}$ indica que desde el punto de vista de la protección de datos, el riesgo reside en la finalidad o finalidades del

13 Definición de cookie dada en la web oficial de la Unión Europea.

https://europa.eu/european-union/abouteuropa/cookies_es

14 Dictamen $2 / 2010$, pág. 7.

15 Únicamente se hará referencia a "las" cookies al citar este documento, pues se refiere a cookies en femenino. En el resto del artículo se hace referencia a "los" cookies pues es el género que se utiliza en la normativa y los documentos de la UE.

16 La primera Guía sobre cookies fue elaborada en 2013 tras la aprobación de la Directiva 2009/135/CE, por la Agencia Española de Protección de Datos (La Agencia Española de Protección de Datos se creó en 1992 y comenzó a funcionar en 1994) en colaboración con asociaciones de autorregulación como la Asociación para la Regulación de la Comunicación Comercial (AUTOCONTROL) o el Interactive Advertising Bureau (iab). La versión actual, de 2019 fruto de la entrada en vigor del RGPD contempla algunas novedades, págs. 7 y 11 respectivamente.

17 Dictamen 4/2012 del GT29 sobre la exención del requisito del consentimiento de cookies, adoptado el 7 de junio de 2012. 00879/12/ES WP 194. 
tratamiento más que en la información contenida en el cookie ${ }^{18}$. Por ello, nos basamos en la clasificación que hacen las "Guías sobre el uso de las cookies" AEPD conforme a su finalidad, dando prioridad a los cookies que, por los datos que recogen y por su duración, al permitir la elaboración de perfiles pueden estar destinadas a la elaboración de publicidad comportamental y por ello suponer un riesgo para la privacidad del usuario.

De su lectura se puede concluir que las dos primeras, los cookies técnicos ${ }^{19}$, y los de preferencias o personalización ${ }^{20}$, no se consideran "intrusivos" y no suponen un riesgo para la privacidad. La tercera, los cookies de análisis ${ }^{21}$ tampoco entrañarían un riesgo salvo si están destinados a la elaboración de perfiles de navegación de los usuarios... con el fin de introducir mejoras en función del análisis de los datos de uso que hacen... del servicio de un sitio concreto. Al permitir la elaboración de perfiles, en caso de ser cookies de análisis de terceros, es decir cookies gestionados desde un dominio distinto a aquél desde el que se presta el servicio solicitado por el usuario, éstas suponen un riesgo notablemente más elevado para la privacidad ${ }^{22}$.

18 Dictamen 4/2012, pág. 6.

19 Los cookies técnicos son aquellos que permiten al usuario la navegación a través de una página web, plataforma o aplicación y la utilización de las diferentes opciones o servicios que en ella existan, incluyendo aquellos que el editor utiliza para permitir la gestión y operativa de la página web y habilitar sus funciones y servicios, como, por ejemplo, controlar el tráfico y la comunicación de datos, identificar la sesión, acceder a partes de acceso restringido, recordar los elementos que integran un pedido, realizar el proceso de compra de un pedido, gestionar el pago, controlar el fraude vinculado a la seguridad del servicio, realizar la solicitud de inscripción o participación en un evento, contar visitas a efectos de la facturación de licencias del software con el que funciona el servicio (sitio web, plataforma o aplicación), utilizar elementos de seguridad durante la navegación, almacenar contenidos para la difusión de vídeos o sonido, habilitar contenidos dinámicos (por ejemplo, animación de carga de un texto o imagen) o compartir contenidos a través de redes sociales. La Guía AEPD 19, págs. 11-12.

${ }_{20}$ Los cookies de preferencias o personalización son aquellos que permiten recordar información para que el usuario acceda al servicio con determinadas características que pueden diferenciar su experiencia de la de otros usuarios, como, por ejemplo, el idioma, el número de resultados a mostrar cuando el usuario realiza una búsqueda, el aspecto o contenido del servicio en función del tipo de navegador a través del cual el usuario accede al servicio o de la región desde la que accede al servicio, etc.. La Guía AEPD 19, pág. 12.

${ }^{21}$ Los cookies de análisis son aquellos que permiten al responsable de los mismas el seguimiento y análisis del comportamiento de los usuarios de los sitios web a los que están vinculadas, incluida la cuantificación de los impactos de los anuncios. La información recogida mediante este tipo de cookies se utiliza en la medición de la actividad de los sitios web, aplicación o plataforma, con el fin de introducir mejoras en función del análisis de los datos de uso que hacen los usuarios del servicio. La Guía AEPD 19, pág. 12.

${ }^{22}$ Dictamen 4/2012, pág. 12. 
Las dos últimas clasificaciones corresponden a cookies publici$\operatorname{tarios}^{23}$ y a cookies de publicidad comportamental. La Guía AEPD de 2019 opta por excluir la categoría de cookies publicitarios de su clasificación, entendiéndose que engloba ambas. La Guía AEPD, los define como aquéllos que permiten la gestión, de la forma más eficaz posible, de los espacios publicitarios que, en su caso, el editor haya incluido en una página web, aplicación o plataforma desde la que presta el servicio solicitado en base a criterios como el contenido editado o la frecuencia en la que se muestran los anuncios. Entendemos que la razón por la que se han unificado es que algunos cookies publicitarios corresponden a cookies técnicos pues están destinados a la gestión de los espacios publicitarios ${ }^{24}$, mientras que otros aunque sean cookies propios recaban datos que son compartidos con fines de publicidad comportamental ${ }^{25}$.

Nos centramos por ello en estos últimos pues son precisamente los que, por estar destinados a fines de publicidad comportamental, presentan características en cuanto a su duración y origen, que permiten el seguimiento continuado de los hábitos de navegación del usuario y la elaboración de perfiles. En cuanto a su duración, suelen estar caracterizados por ser cookies persistentes y no de sesión, esto es, tienen una fecha de expiración que se traslada al futuro entendiéndose éste por un momento posterior a aquél en que el usuario cierra el navegador que está utilizando incluso pudiendo no tener asignada una fecha de expiración por lo que permanecen en el terminal y están operativos por periodos extensos que pueden ser minutos, días o incluso años ${ }^{26}$. En lo que se refiere a su origen, éstos suelen ser de terceros por lo que recaban datos para un responsable del tratamiento de los datos distinto a aquél que opera el sitio web visitado por el usuario ${ }^{27}$.

23 Guía sobre el uso de las cookies de 2013, pág. 8.

24 La Guía AEPD 2013 los definía como aquéllos que "permiten la gestión, de la forma más eficaz posible, de los espacios publicitarios que, en su caso, el editor haya incluido en una página web, aplicación o plataforma desde la que presta el servicio solicitado en base a criterios como el contenido editado o la frecuencia en la que se muestran los anuncios", pág. 9.

25 Tal y como indica la Guía AEPD 2019, "en el caso de que las cookies sean servidas desde un equipo o dominio gestionado por el propio editor, pero la información que se recoja mediante estas sea gestionada por un tercero, no pueden ser consideradas como cookies propias si el tercero las utiliza para sus propias finalidades (por ejemplo, la mejora de los servicios que presta o la prestación de servicios de carácter publicitario a favor de otras entidades)", pág. 11.

26 Dictamen 4/2012, pág. 4.

27 Dictamen 4/2012, pág. 5. 
Finalmente, y dada su controversia, cabe destacar los denominados flash cookies ${ }^{28}$, que presentan la particularidad de que no se instalan en el navegador del usuario, sino en otra localización del dispositivo $^{29}$ a diferencia del resto de cookies o cookies tradicionales. A la vez, constituyen una forma reforzada de rastreo al tener la habilidad de restaurar o regenerar cookies tradicionales (instalados en el navegador), incluidos los de publicidad comportamental, incluso si éstos han sido rechazados o borrados por el usuario ${ }^{30}$.

Dada la complicación que supone clasificar los cookies y determinar cuáles posibilitan la publicidad comportamental, establecer un régimen jurídico que proteja la privacidad de los usuarios resulta difícil. A ello se una la convergencia que generan los cookies a su alrededor puesto que tanto éstos como la información que recaban se transmiten a través de redes de comunicaciones electrónicas y además algunos de ellos están destinados a posibilitar la prestación de servicios de la Sociedad de la información. Como se verá a continuación, en este contexto ha sido necesario, a través de sucesivos cambios normativos, elevar nivel de protección de la privacidad de los usuarios.

\section{EVOLUCIÓN DEL MARCO JURÍDICO: SISTEMAS OPT-IN Y OPT-OUT.}

El marco jurídico actual por el que se regula la instalación de cookies, y en concreto los que permiten la publicidad comportamental, en los terminales de los usuarios descansa sobre la Directiva 2002/58/CE ${ }^{31}$ sobre la privacidad y las comunicaciones electrónicas, y está basado en el principio del consentimiento del usuario conforme a la definición dada actualmente en el Reglamento 2016/679/ $\mathrm{UE}^{32}$ general de protección de datos personales (en adelante, RGPD)

28 SOLTANI, A., CANTY, S., MAYO, Q., THOMAS, L., \& HOOFNAGLE, C. J., "Flash cookies and privacy", 2010 AAAI (Association for the Advancement of Artificial Intelligence) Spring Symposium Series, marzo de 2010, pág. 158.

29 Dependiendo del sistema operativo del terminal los cookies se alojarán en una carpeta u otra del terminal. Vid. SOLTANI, A., CANTY, S., MAYO, Q., THOMAS, L., \& HOOFNAGLE, C. J. "Flash cookies and privacy”, 2009, pág. 2. Disponible en SSRN 1446862

30 La Guía AEPD 2013, pág. 5 y La Guía AEPD 2019, nota a pie 8, pág. 8.

31 Directiva 2002/58/CE, págs. 37 - 47.

32 Reglamento (UE) 2016/679 del Parlamento Europeo y del Consejo de 27 de abril de 2016 relativo a la protección de las personas físicas en lo que respecta al tratamiento de datos personales y a la libre circulación de estos datos y por el que se deroga la Directiva 95/46/CE, DOL 119 de 4.5.2016, págs. 1-88. 
que derogó la Directiva 95/46/CE ${ }^{33}$ de protección de datos (en adelante, Directiva 95/46/CE).

No siempre fue así, a partir de la aprobación de la directiva 95/46/CE propiciado por la convergencia tecnológica encontramos, en las regulaciones sectoriales de servicios de la sociedad de la información y de las telecomunicaciones, normas relativas a la publicidad y a la publicidad no deseada que convergen también jurídicamente. La Directiva 95/46/CE dejaba clara su horizontalidad al indicar en su aplicación al primero en su CDO 14, y al segundo en su CDO 47. La Directiva 97/66/CE ${ }^{34}$ perteneciente al sector de las telecomunicaciones, aludía específicamente a la aplicación de la Directiva 95/46/CE en su DCO 11, y la Directiva 2000/31/CE ${ }^{35}$ no sólo hacía lo mismo en su CDO 14 sino que también establecía que la Directiva 97/66/CE era aplicable a los servicios de la sociedad de la información. Además, el art. 1.5 Directiva 2000/31/CE reconocía que las Directivas 95/46/CE y 97/66/CE contenían cuestiones relacionadas con los servicios de la sociedad de la información, estableciendo que para esas cuestiones no se aplicaría la Directiva 2000/31/CE. Se dejaba ver por tanto la convergencia entre ambos sectores, en torno a los fines comerciales de las comunicaciones, en realidad publicidad, que daría paso más adelante, a la modalidad de publicidad comportamental con la regulación de los cookies.

La Directiva 97/66/CE contenía diferentes disposiciones, aplicables a cuestiones relacionadas con la publicidad o los fines publicitarios, que aludían a la instauración del sistema opt-in en los arts. 6.3 y 11, incluyendo el segundo el derecho del usuario a ser excluido (art 11.1) o retirar "a petición propia" el consentimiento dado a través de

33 Directiva 95/46/CE del Parlamento Europeo y del Consejo, de 24 de octubre de 1995, relativa a la protección de las personas físicas en lo que respecta al tratamiento de datos personales y a la libre circulación de estos datos. DO L281 de 23.11.1995, págs. 31-50.

${ }^{34}$ Directiva 97/66/CE del Parlamento Europeo y del Consejo de 15 de diciembre de 1997 relativa al tratamiento de datos personales y la protección de la intimidad en el sector de las telecomunicaciones, Diario Oficial n L 024 de 30/01/199, págs. 1-8.

35 Directiva 2000/31/CE del Parlamento Europeo y del Consejo de 8 de junio de 2000 relativa a determinados aspectos jurídicos de los servicios de la sociedad de la información, en particular el comercio electrónico en el mercado interior (Directiva sobre el comercio electrónico) DO L 178 de 17.7.2000, págs. 1-16. La Ley 34/2002, de 11 de Julio de servicios de la sociedad de la información y de comercio electrónico también supuso la transposición al ordenamiento jurídico español de la Directiva 98/27/CE del Parlamento Europeo y del Consejo de 19 de mayo de 1998 relativa a las acciones de cesación en materia de protección de los intereses de los consumidores (derogada por la por Directiva 2009/22). 
las listas Robinson ${ }^{36}$. A destacar por su especial importancia en la evolución de los sistemas opt-in y opt-out, fue el art. 12 que constituye una nueva alusión a los fines publicitarios. Mientras que el art. 12.1 establecía claramente un sistema opt-in, el art.12.2 permitía a los EEMMs elegir al trasponer la norma a sus legislaciones nacionales, entre imponer un sistema opt-in o un sistema opt-out. Las facultades y el margen de discrecionalidad conferidos a los EEMMs daría origen a una transposición heterogénea.

En paralelo, el art. 7.2 Directiva 2000/31/CE relativo a las comunicaciones comerciales no solicitada ${ }^{37}$ realizadas por correo electrónico, permite a los EEMMs transponer el precepto a sus legislaciones nacionales optando por prohibirlos o no. En caso de no prohibirlos se alude de forma expresa a la adopción de un sistema opt-out. El hecho de que el mismo precepto indique que los EEMMs son los garantes de la materialización de este sistema, sin perjuicio de lo establecido en la Directiva 97/66/CE, ligaba íntimamente ambas Directivas evidenciando nuevamente la convergencia entre ambos sectores.

Esta relación se mantuvo tras la derogación de la directiva 97/66/ CE y su sustitución por la Directiva 2002/58/CE. En ella se estableció la regulación específica de cookies basado en un sistema opt-out, por lo que, si bien las modificaciones introducidas por la Directiva 2002/58/CE en las comunicaciones electrónicas con fines publicitarios evidenciaron de nuevo la convergencia y el cruce entre los sectores de las telecomunicaciones y de la sociedad de la información tanto a nivel europeo como nacional a través de los artículos 21 y 22

36 La respuesta del Sr. Byrne en nombre de la Comisión de 30 de septiembre de 2002 a la pregunta escrita E-2344/02 sobre correo no deseado, indica que las listas de exclusión voluntaria son también conocidas como listas Róbinson. Si bien alude a la Directiva 2002/58/CE dado que sería aplicable a partir del 31 de octubre de 2003, entendemos que las remisiones son válidas para la Directiva 97/66/CE puesto que ésta todavía estaba en vigor. https://eur-lex.europa.eu/LexUriServ/LexUriServ.do ?uri=OJ:C:2003:052E:0156:0157:ES:PDF

37 La definición de comunicación comercial se establece en el artículo $2 \mathrm{f}$ ) de la Directiva 2000/31/CE como todas las formas de comunicación destinadas a proporcionar directa o indirectamente bienes, servicios o la imagen de una empresa, organización o persona con una actividad comercial, industrial, artesanal o de profesiones regulada. A su vez, el articulo 2 a) de la Directiva 2006/114/CE del Parlamento Europeo y del Consejo, de 12 de diciembre de 2006, sobre publicidad engañosa y publicidad comparativa $O J$ L 376, 27.12.2006, p. 21-27, define la publicidad como toda forma de comunicación realizada en el marco de una actividad comercial, industrial, artesanal o liberal con el fin de promover el suministro de bienes o la prestación de servicios, incluidos los bienes inmuebles, los derechos y las obligaciones. Ambas definiciones resultan muy similares por lo que se podría sostener que las primeras son una forma de publicidad. 
de la LSSI-CE ${ }^{38}$, a partir de ahora nos centraremos únicamente en el régimen de cookies.

La redacción del art. 5.3 de la Directiva 2002/58/CE, diferenció entre dos categorías de cookies. La primera, respecto de la que se estableció un sistema opt-out, incluía los cookies que posibilitan la elaboración de publicidad comportamental. Se indicaban, como únicas condiciones para su instalación que se facilitase al usuario información clara y completa, en particular sobre los fines del tratamiento de los datos, con arreglo a lo dispuesto en la Directiva 95/46/CE. Por tanto, siempre que se ofreciera la información, el cookie se instalaría en el terminal del usuario independientemente de que éste la hubiera leído o no. A la vez, el responsable del tratamiento de los datos tenía la obligación de ofrecerle el derecho de negarse a dicho tratamiento. La posibilidad de ejercer el derecho de oposición, implica que el usuario debía solicitar que sus datos no fuesen objeto de tratamiento en un momento posterior a su instalación. La segunda, incluía tanto aquéllos destinados a efectuar o facilitar la comunicación como aquéllos destinados a proporcionar la información necesaria para suministrar un servicio expresamente solicitado por el usuario. En estos supuestos no se impedirá el posible almacenamiento o acceso de índole técnica Así, bien no resultaba necesario informar sobre éstas, bien no se podía ejercer el derecho a negarse al tratamiento, por lo que no había sistema opt-out, simplemente estaban permitidos.

La irrupción de los cookies a través del art. 5.3 Directiva 2002/58/ CE puso en evidencia la convergencia sectorial, por cuanto los cookies que facilitan la prestación de servicios de la información, quedaban regulados en el sector de las telecomunicaciones. Se apreciaba un nuevo cruce entre ambos sectores, que también afectó a la transposición de la norma a nuestro sistema normativo nacional ${ }^{39}$.

\section{III.A. Adopción del sistema opt-in ante el uso de cookies de publicidad comportamental.}

La creciente accesibilidad a internet, y la multiplicación en el uso de cookies, en especial aquéllos de publicidad comportamental aumentaba los supuestos en que la privacidad del usuario se ponía en

38 Ley 34/2002, de 11 de Julio de servicios de la sociedad de la información y de comercio electrónico LSSI-CE. BOE núm. 166, de 12/07/2002.

39 La disposición final 1.1 de la Ley 32/2003, de 3 de noviembre, General de Telecomunicaciones (BOE 4 de noviembre 2003 BOE núm. 264). Derogada el 11 de mayo de 2014 por la Ley 9/2014 de 9 de mayo General de Telecomunicaciones, modificó el art. 22 de la LSSI-CE perteneciente al sector de la sociedad de la información. 
riesgo, especialmente ante una regulación basada en un sistema optout. La aprobación de la Directiva $2009 / 136 / \mathrm{CE}^{40}$ por la que se modificó la Directiva 2002/58/CE admitía que sólo algunos tipos de cookies perseguían un fin legítimo, reconociendo, de forma implícita la existencia de cookies de publicidad comportamental. Se justificaba así el paso al sistema opt-in para este tipo de cookies, en un intento por contribuir a reforzar el derecho a la protección de los datos personales de los usuarios de internet.

Las modificaciones introducidas en la primera oración art. 5.3 establecieron el requisito del consentimiento previo, por cuanto solamente estaría permitido el almacenamiento de información o el acceso a aquélla que ya estuviera almacenada en el terminal del usuario (a través de cookies), a condición de que dicho abonado o usuario hubiera dado su consentimiento, con arreglo a lo dispuesto en la Directiva 95/46/CE, después de que se le hubiera facilitado información clara y completa, en particular sobre los fines del tratamiento de los datos. La validez del consentimiento otorgado quedaba supeditada al deber previo de información respecto de los fines del tratamiento, a la vez que se determinaba que ésta se facilitase de forma clara y completa. Nuevamente la segunda oración del art. 5.3 reproducía su contenido permitiendo el uso de cookies necesarios para la prestación de un servicio, por lo que estos supuestos quedaban fuera del sistema opt-in.

En un intento por minimizar los efectos que pudieran derivarse a nivel práctico de la necesidad de prestar el consentimiento, el CDO 66 Directiva 2009/136/CE aludía a la posibilidad de que éste se prestase mediante el uso de los parámetros adecuados del navegador o de otra aplicación (entendiéndose como tales los ajustes de privacidad). Como se verá más adelante, lejos contribuir a reforzar la privacidad de los usuarios, contribuyó a aumentar los casos de incumplimiento, puesto que en algunos casos como el nuestro, la transposición de la norma incluyó este supuesto ${ }^{41}$.

40 Directiva 2009/136/CE del Parlamento Europeo y del Consejo, de 25 de noviembre de 2009, por la que se modifican la Directiva 2002/22/CE relativa al servicio universal y los derechos de los usuarios en relación con las redes y los servicios de comunicaciones electrónicas, la Directiva 2002/58/CE relativa al tratamiento de los datos personales y a la protección de la intimidad en el sector de las comunicaciones electrónicas y el Reglamento (CE) n o 2006/2004 sobre la cooperación en materia de protección de los consumidores, OJ L 337, 18.12.2009, págs. 11-36.

41 El Real Decreto-ley 13/2012 de 30 de marzo, por el que se transponen directivas en materia de mercados interiores de electricidad y gas y en materia de comunicaciones electrónicas, y por el que se adoptan medidas para la corrección de las desviaciones por desajustes entre los costes e ingresos de los sectores eléctrico y gasista. BOE núm. 78, de 31 de marzo de 2012, páginas 26876 a 26967 (92 págs.), 
La derogación de la Directiva 95/46/CE fruto de la aprobación del RGPD supuso la modificación del marco de protección de las personas físicas en lo que respecta al tratamiento de datos personales que había permanecido constante ${ }^{42}$ durante más de veinte años. De aplicación directa y destinada a fijar un marco jurídico único y general y así armonizar la normativa de los EEMM. El RGPD estableció nuevos supuestos de datos que se consideran de carácter personal y añadió un nuevo requisito con carácter general para que el consentimiento fuese válido lo que incidió en la aplicación del art. 5.3 Directiva 2002/58/CE, a la vez que, añadía la necesidad de que ésta fuese revisada y modificada con el objetivo de garantizar la coherencia con el RGPD ${ }^{43}$.

\section{III.B. Relación entre la directiva 2002/58/CE y la normativa sobre protección de datos personales.}

La modificación introducida por la Directiva 2009/136/CE supuso el paso del sistema opt-out al opt-in en el régimen aplicable a los cookies, permaneciendo vinculado a la Directiva 95/46/CE hasta su derogación por el RGPD, puesto que el art. 5.3 remite a la definición del consentimiento contenida en la normativa sobre protección de datos. La doctrina según la cual una ley que regula una materia específica (lex specialis) prima sobre una ley que regula una materia general (lex generalis), supone que el art. 5.3 Directiva

modificó a través de su artículo 4 apartado 3 la Ley34/2002 de servicios de la sociedad de la información y de comercio electrónico (LSSI-CE). Esta norma perteneciente al sector de las telecomunicaciones no sólo puso nuevamente de manifiesto la convergencia entre los sectores de las telecomunicaciones y la sociedad de la información y supuso un tercer cruce entre ambos, sino que introdujo, a diferencia de la Directiva 2009/36/CE, la posibilidad de que el consentimiento se facilitase mediante el uso adecuado de parámetros de los navegadores y otras aplicaciones indicando que debía ser el usuario quien configurase sus preferencias de privacidad mediante la realización de una acción expresa. Tal y como se desprende de la lectura del párrafo segundo el artículo 22.2 de la LSSI-CE, se establecían dos posibilidades para prestar el consentimiento: La primera que los proveedores de servicios de internet proporcionasen al usuario sistemas para el otorgamiento del consentimiento informado, y la segunda que los propios usuarios determinasen el nivel de protección frente a los cookies a través de la configuración de los parámetros de privacidad de sus navegadores.

42 DE HERT, P., PAPAKONSTANTINOU, V., "The proposed data protection Regulation replacing Directive 95/46/EC: A sound system for the protection of individuals", Computer law \& Security review, 28, 2012, págs. 130-142.

43 CDO 173 RGPD: Para aclarar la relación entre el presente Reglamento y la Directiva 2002/58/CE, esta última debe ser modificada en consecuencia. Una vez que se adopte el presente Reglamento, debe revisarse la Directiva 2002/58/CE, en particular con objeto de garantizar la coherencia con el presente Reglamento. 
2002/58/CE será directamente aplicable al régimen de cookies y el RGPD al tratamiento de los datos de carácter personal cuando no estén regulados por la Directiva 2002/58/CE ${ }^{44}$. En consecuencia, el desencadenante de las obligaciones contenidas en el art. 5.3 es la protección de la esfera privada del usuario, no el hecho de que los datos sean personales o no ${ }^{45}$. La aplicación del art. 5.3 afecta a la información en sí, a los datos en general y, por tanto, a los cookies como instrumento que permite acceder a ella o almacenarla, independientemente de que los datos sean de carácter personal o no puesto que a tenor del CDO 24 Directiva 2002/58/CE los equipos terminales de los usuarios así como toda la información almacenada en ellos, forman parte de la esfera privada de los usuarios y ésta debe ser protegida.

Para dar cumplimiento al art. 5.3 es necesario atender a la definición de consentimiento del interesado dada por el RGPD, pero el ámbito de aplicación del RGPD sólo se activa tal como expone su CDO 26, cuando la información relativa a una persona física la identifique o permita identificarla. En este caso, en consonancia con la definición dada por el art 4.1 RGPD ${ }^{46}$, los datos serán personales. Este es el caso de los datos recabados por cookies de publicidad comportamental, puesto su tratamiento permite construir un perfil que aísla al usuario de los demás aun desconociéndose su nombre verdadero $^{47}$. Este perfil contiene información específica relativa a su comportamiento en internet, sus gustos y características personales. En consecuencia, cuando estemos ante cookies de publicidad comportamental siempre se activará la aplicación del RGPD.

44 El CDO 173 RGPD afirma que debe aplicarse a todas las cuestiones relativas a la protección de los derechos y las libertades fundamentales en relación con el tratamiento de datos personales que no estén sujetas a obligaciones específicas con el mismo objetivo establecidas en la Directiva 2002/58/CE (modificada por la Directiva 2009/136/CE) incluidas las obligaciones del responsable del tratamiento y los derechos de las personas físicas.

45 Dictamen 2/2010 GT29, pág. 9.

46 Art.4.1 RGPD: toda información sobre una persona física identificada o identificable (el interesado); se considerará persona física identificable a toda persona cuya identidad pueda determinarse directa o indirectamente, en particular mediante un identificador, como por ejemplo un nombre, un número de identificación, datos de localización, un identificador en línea o uno o varios elementos propios de la identidad física, fisiológica, genética, psíquica, económica, cultural o social de dicha persona.

47 Vid. Dictamen 2/2010 GT29, pág. 10 para información relativa a la construcción y tipos de perfiles. 


\section{APLICACIÓN DEL ART. 5.3 DE LA DIRECTIVA 2002/58/CE}

La transposición de la Directiva 2009/136/CE, fue objeto de diferente interpretación por parte de las normativas nacionales de los EEMMs. En la mayoría de los EEMMs la norma estableció el primero consistente con un sistema opt-in, mientras que por ejemplo, Finlandia y Luxemburgo adoptaron el sistema opt-out ${ }^{48}$. En el caso concreto de España, como ya se ha visto en el punto III.A., la transposición de la norma supone la convivencia de ambos. Su aplicación desde un punto de vista práctico, dio lugar a la coexistencia de distintos avisos de cookies en páginas web que articulaban diferentes mecanismos para otorgar el consentimiento. Por una parte se seguían utilizando avisos de cookies que daban cumplimiento a la normativa anterior (opt-out), y por otro, aparecieron nuevos avisos de cookies basados en el sistema opt-in que pretendían dar cumplimiento al art.5.3 modificado por la Directiva 2009/136/CE. Dentro de estos últimos se podían diferenciar dos tipos: unos que solicitan el consentimiento del usuario para la instalación de cookies tras haberle informado de sus características y finalidades, y otros que remiten al usuario la configuración de los parámetros de privacidad del navegador para otorgar el consentimiento.

La convivencia de todos ellos, unido a la falta de información clara y detallada acerca de la forma y características de los avisos de cookies basados en un recién establecido sistema opt-in, generaba confusión en aquéllos que tenían la obligación de utilizarlos y en sus destinatarios, a la vez que supuso la existencia de diferentes versiones o modalidades que en muchos casos incluso en la actualidad no cumplen la norma. El GT29, en su Dictamen 2/2010 sobre publicidad comportamental en línea, se propuso aclarar el nuevo marco jurídico aplicable a quienes utilizan cookies de publicidad comportamental a la vez que facilitar y fomentar la observancia del mismo ${ }^{49}$

Por otro lado, existían dudas en torno a qué cookies habían de someterse de forma previa a los requisitos de información y consentimiento y cuáles no. Resulta importante hacer hincapié en que los avisos de cookies basados en el sistema opt-in, no son aplicables a todos los tipos de cookies. Recordemos que en el punto III hacíamos la distinción entre dos categorías diferenciadas de cookies según estuvieran comprendidos en la primera o en la segunda oración del art. 5.3. La distinción entre ambas categorías también generó con-

48 Monopolkomission report, 'Competition policy: The challenge of digital markets', 2015, págs. 33-34.

49 Dictamen 2/2010, resumen, párrafo primero, pág. 3. 
fusión por lo que el GT29 en su Dictamen 4/2012 aclaró los tipos de cookies que no han someterse al sistema opt-in.

Finalmente se generaban dudas relativas a los requisitos que han de cumplir los avisos de cookies consistentes con un sistema opt-in, y por tanto a la interpretación de la definición del consentimiento. En un primer momento el Documento de trabajo 2/2013 ${ }^{50}$ GT29 clarificó los requisitos para que el consentimiento se considerase válido conforme a la definición dada por la Directiva 95/46/CE, mientras que, tras la entrada en vigor del RGPD es el Comité Europeo de Protección de Datos ${ }^{51}$ (en adelante CEPD), quién a través de sus Directrices ha hecho lo propio.

Por ello, procedemos a aclarar estas dudas, en primer lugar aquéllos cookies que quedan sometidos al consentimiento del usuario para su instalación, en segundo los requisitos que se han de cumplir para que el consentimiento sea válido, y finalmente describir los avisos de cookies, distinguiendo entre sus diferentes modalidades y aquéllos que consideramos más apropiados para dar cumplimiento al art.5.3.

\section{IV.A. Cookies sujetos a los requisitos de información y consentimiento previo.}

Las dudas, y con ello la problemática que surgía en torno a qué cookies debían estar sometidos al sistema opt-in y cuáles no conforme al art. 5.3 de la Directiva 2009/136/CE fueron aclaradas por el Dictamen 4/2012 del GT2952 sobre la exención del requisito del consentimiento. En él se hace una clasificación clara de cookies conforme a la finalidad que persiguen y se establecen qué cookies quedan "exentos" del requisito del consentimiento informado conforme a dos criterios. Éstos, A y B, corresponden a los supuestos contemplados en la segunda oración del art. 5.3 que indica que... no impedirá el posible almacenamiento o acceso de índole técnica al solo fin de efectuar la transmisión de una comunicación a través de una red de comunicaciones electrónicas, o en la medida de lo estrictamente necesario

50 Working Document 02/2013 of Article29 Data Protection Working Party providing guidance on obtaining consent for cookies, adopted on 2 October 2013, 1676/13/ENWP 208.

51 El Comité europeo de rotección de datos, sustituyó al ahora extinto GT29 tras la entrada en vigor del RGPD.

52 Dictamen 4/2012 del Grupo de Trabajo sobre protección de datos del artículo 29 sobre la exención del requisito de consentimiento de Cookies de 7 de julio de 2012, 00879/12/ES WP 194, pág. 3. 
a fin de que el proveedor de un servicio de la sociedad de la información preste un servicio expresamente solicitado por el abonado o el usuario.

La primera categoría conocida como criterio A, exige que el cookie sea estrictamente necesario para que se produzca la transmisión de la comunicación, no resultando suficiente que éste contribuya a ayudar, agilizar o regular dicha transmisión ${ }^{53}$. Se entiende que dicha transmisión se produce a través de una red de comunicaciones electrónicas conforme a la definición dada en la Directiva 2002/21/CE ${ }^{54}$. En consecuencia los cookies permitidos podrían calificarse como cookies de carácter técnico ${ }^{55}$.

La segunda categoría, conocido como criterio B, establece que el cookie deberá reunir dos requisitos de manera simultánea. El primero, que el servicio haya sido solicitado de manera expresa por el usuario, lo cual exige a su vez que el usuario haya realizado una acción positiva expresando así dicha solicitud. El segundo, que la instalación del cookie sea estrictamente necesaria para que pueda prestarse el servicio solicitado, entendiéndose que si el cookie no funciona no podrá prestarse el servicio ${ }^{56}$.

En cualquier caso, y para ambos criterios, para determinar si el cookie está exento o no, se deberá tener en cuenta su finalidad más que la información contenida en el propio cookie. Por tanto, independientemente de que se cumplan los criterios, si el cookie permite seguir a los usuarios a través de un dominio y ofrecer contenidos adaptados o publicidad basada en el perfil que obre en poder del

53 La redacción original dada en la directiva 2002/58/CE al solo fin de efectuar o facilitar incluía la palabra facilitar, que fue suprimida por la Directiva 2009/136 clarificando y limitando este supuesto de exención del requisito del consentimiento.

54 Directiva 2002/21/CE del Parlamento Europeo y del Consejo, de 7 de marzo de 2002, relativa a un marco regulador común de las redes y los servicios de comunicaciones electrónicas (Directiva marco) DO L 108 de 24.4.2002, pág. 33.

55 Para que la cookie quede exenta ha de cumplir al menos uno de los siguientes criterios; posibilitar el envío de la información a través de la red, especialmente mediante la identificación de los extremos de la comunicación; posibilitar el intercambio datos en un orden previsto, especialmente mediante la numeración de paquetes de datos, y; posibilitar la detección de errores de transmisión o pérdidas de datos. Dictamen 4/2012 del Grupo de Trabajo sobre protección de datos del artículo 29 sobre la exención del requisito de consentimiento de Cookies de 7 de julio de 2012, 00879/12/ES WP 194, pág. 3.

56 El CDO (66) de la Directiva 2009/136/CE especifica que las excepciones a la obligación de facilitar información y proponer el derecho de negativa deben limitarse a aquellas situaciones en las que el almacenamiento técnico o el acceso sean estrictamente necesarios con el fin legítimo de permitir el uso de un servicio específico solicitado específicamente por el abonado o usuario. 
operador del sitio web, no estará exento ${ }^{57}$. Sin embargo, el usuario no tiene forma de saber qué cookies tienen por finalidad la elaboración de publicidad comportamental puesto que el uso de cookies supone una captación invisible de información ${ }^{58}$. Salvo las indicaciones en este sentido de aquél que pretende instalarlo entendemos que el usuario está desprotegido.

\section{IV.B. requisitos de validez del consentimiento para cookies de publicidad comportamental.}

Como hemos visto, el usuario ha de prestar su consentimiento para la instalación de cookies de publicidad comportamental conforme a la primera oración del art. 5.3. Su definición inicialmente dada en la Directiva 95/46/CE fue modificada por el RGPD. Se establecieron pues dos momentos diferenciados puesto que el RGPD la modificó incluyendo la necesidad de que este se prestase de forma inequívoca, Sin embargo, la inclusión de este requisito adicional no afecta a los cookies de publicidad comportamental, pues como hemos visto, los datos que recaban tienen la consideración de personales pues su tratamiento permite la elaboración de un perfil que aísla o permite identificar al usuario. En este sentido la Directiva 95/46/CE establecía que cuando los datos recabados tuvieran carácter personal éstos únicamente podían ser tratados cuando el consentimiento del usuario se hubiera dado de forma inequívoca (art.7.a).

El Documento de trabajo 2/2013 ${ }^{59}$ GT29 clarificó en un primer momento los requisitos para un consentimiento válido conforme a la definición de la Directiva 95/46/CE. Para ello determinó sus elementos principales: la manifestación de la voluntad libre, específica, e informada ${ }^{60}$. A su vez aclaró que la manifestación de la voluntad

57 Las categorías de cookies que no quedan exentas pueden consultarse en el Dictamen 4/2012 GT29, págs. 10-12.

58 LÓPEZ-LAPUENTE GUTIÉRREZ, L., "El uso de cookies en España a la luz de la guía sobre el uso de las cookies de la agencia española de protección de datos", Actualidad Jurídica Uría-Menéndez, septiembre-diciembre 2013 1578-956X, no.35. 2013, pág. 93.

${ }_{59}$ Working Document 02/2013 of Article29 Data Protection Working Party providing guidance on obtaining consent for cookies, adopted on 2 October 2013, 1676/13/ENWP 208.

60 Para que, tanto la información, como la manifestación de la voluntad sea específica, los usuarios no sólo deben recibir toda la información necesaria acerca de los tipos de cookies, su finalidad, duración y origen, sino también cómo pueden aceptar todos los cookies, como aceptar únicamente algunas categorías o como rechazarlos todos y el modo en que pueden cambiar sus preferencia en el futuro, sino que la información ha de proporcionarse con anterioridad a la obtención del con- 
necesitaría constituir un acto explícito para asegurar que el consentimiento sea inequívoco en cumplimiento del art 7.a. coincidiendo con lo expresado en el Dictamen 2/2010. Esto supone realizar una acción positiva o un comportamiento activo, a lo que se unía la necesidad de prestar el consentimiento con carácter previo a la instalación del cookie ${ }^{61}$.

La aprobación del RGPD ha ampliado la definición del consentimiento (art. 4.11 del RGPD) aportando un cuarto elemento a los que ya figuraban en la definición dada por la Directiva 96/46/CE. A los elementos que inicialmente condicionaban la validez del consentimiento, manifestación libre, específica, e informada se une la necesidad de que ésta sea inequívoca. En este sentido, la información recabada por los cookies, constituya o no datos personales ha de cumplir con todos ellos ${ }^{62}$. Las Directrices 05/2020 sobre el consentimiento ${ }^{63}$ del Comité Europeo de Protección de Datos ${ }^{64}$ (en adelante CEPD), han descrito los cuatro elementos del consentimiento válido ${ }^{65}$.

El primer elemento, la necesidad de que la manifestación sea libre, implica que los usuarios tengan una capacidad de elección real y retengan el control sobre sus elecciones. Si el usuario no puede elegir libremente, se siente obligado a dar su consentimiento, o cuando no prestarlo puede comportar efectos negativos, el consen-

sentimiento. La oportunidad del usuario de elegir libremente ha de ser real, por lo que al acceder a una página web se debe tener la oportunidad de elegir si aceptar todos o algunos cookies o rechazar todos o algunos.

61 Para una información detallada acerca de la determinación de que los requisitos de información específica, consentimiento previo, expresión de la voluntad del usuario a través de un comportamiento activo y la habilidad de elegir libremente consultar el Documento de trabajo 2/2013 del GT29, págs. 3-6.

62 Recordemos que la necesidad de que el consentimiento fuese inequívoco para el tratamiento de datos sólo era predicable respecto de aquellos datos que fuesen personales de acuerdo con el art. 7 a) de la Directiva 96/46/CE. Ahora se hace extensible a todos aquellos datos que formen parte de la información sometida al art. 5.3 de la Directiva 2002/58/CE.

63 Directrices 05/2020 sobre el consentimiento en el sentido del reglamento 2016/679 Versión 1.1, adoptado el 4 de mayo de 2020, por el Comité Europeo de protección de Datos.

${ }^{64}$ El Comité Europeo de protección de Datos fue creado por el artículo 68 del RGPD y supuso la desaparición del Grupo de Trabajo para la protección de datos del artículo 29 de la Directiva 95/46/CE.

65 El contenido de las Directrices 05/2020 ya fueron anticipadas antes de la aprobación del RGPD por el GT29 en dos documentos: Working Document 2/2013 providing guidance on obtaining consent for cookies y en las Directrices sobre el consentimiento en el sentido del Reglamento (UE) 2016/679 del Grupo de Trabajo del artículo 29 sobre protección de datos adoptadas el 28 de noviembre de 2017 (revisadas por última vez y adoptadas el 10 de abril de 2018, 17/ESWP259 y rev.01. 
timiento no será válido ${ }^{66}$. Sirva de ejemplo en este contexto el hecho de condicionar la aceptación de cookies de publicidad comportamental a la suscripción de una plataforma de venta de productos online. Estos cookies no son necesarios para prestar el servicio de venta ofrecido, y la suscripción no podrá hacerse efectiva salvo que se preste el consentimiento. Puesto que las solicitudes de consentimiento no están disociadas, el usuario no puede elegir libremente, puede sentirse obligado a dar su consentimiento de forma global, y de no hacerlo, los efectos negativos derivados serán la imposibilidad de realizar compras a través de esa plataforma ${ }^{67}$. Si este fuera el caso, de acuerdo con el art. 7.4 del RGPD al evaluar si el consentimiento se ha dado libremente se tendrá en cuenta el hecho (entre otras cosas) de si la prestación de un servicio se supedita al consentimiento al tratamiento de datos personales que no son necesarios para la prestación del servicio.

El segundo elemento, que supone que la manifestación de la voluntad sea específica, conservada de la redacción anterior, se relaciona con el art. 6.1 RGPD por cuanto éste confirma que el consentimiento debe darse para uno o tantos fines específicos, entendiéndose que el interesado podrá elegir respecto a cada uno de esos fines (disociación de las solicitudes del tratamiento).

El tercero, la manifestación de la voluntad informada únicamente es posible cuando el usuario es capaz de tomar decisiones una vez haya recibido la información necesaria para entender aquéllos fines del tratamiento para los que está prestando su consentimiento. En caso contrario el consentimiento no será válido y el responsable o controlador podrá estar incumpliendo el art. 6 RGPD.

Finalmente, el nuevo elemento introducido por el RGPD que indica que la manifestación de voluntad ha de ser inequívoca refuerza el contenido del art. 5.3 de la Directiva 2002/58/CE. Al introducirse los términos inequívoca, acepta, y mediante una declaración o una clara acción afirmativa y suprimirse mediante la que el interesado consienta se descarta taxativamente la posibilidad de otorgar el consentimiento por inacción ante cualquier tipo de datos, sean estos sometidos a tratamiento o no. El establecimiento de que el con-

${ }^{66}$ Directrices 05/2020 sobre el consentimiento en el sentido del reglamento 2016/679 Versión 1.1, adoptado el 4 de mayo de 2020, por el Comité Europeo de protección, pág. 7 .

67 Vid. Directrices 05/2020.El elemento de la manifestación libre está vinculado al condicionamiento de la voluntad, la disociación de las finalidades del tratamiento y a los posibles perjuicios de la manifestación de la voluntad. Para otros ejemplos en los que el consentimiento no se consideran válidamente otorgados, págs. 8 -13. 
sentimiento sólo puede otorgarse mediante una acción o una declaración, caracterizadas ambas por la obligación de ser claras y afirmativas $^{68}$ responde a la obligación impuesta al responsable del tratamiento de datos personales de ser capaz de demostrar en su caso que el usuario prestó su consentimiento en el art. 7.1 del RGPD.

Una vez establecidos los elementos necesarios para que el consentimiento se considere válidamente otorgado podemos, estableciendo un paralelismo con el formato de información por capas de La Guía AEPD 2019, indicar los contenidos mínimos que han de tener los mecanismos de aceptación previos o declaraciones.

\section{AVISOS DE COOKIES}

Como se ha visto, la aplicación del art. 5.3 dio lugar a la coexistencia de diferentes modalidades de avisos de cookies como mecanismo para obtener el consentimiento del usuario a la instalación de cookies. El Dictamen 2/2010 explica los diferentes mecanismos que permiten recabar el consentimiento del usuario. Compartimos con el Dictamen 2/2010 GT29 la convicción que los avisos de cookies que denomina "mecanismos de aceptación previa"69 son los más adecuados para dar cumplimiento al artículo 5.3, en concreto porque éstos permiten exigir un acto explícito del usuario que exprese su consentimiento antes de que se le envíe el cookie ${ }^{70}$, El Dictamen a la vez que indica que aquéllos basados en las configuraciones de privacidad de los buscadores en rara ocasión resultan válidos. Como se verá más adelante somos de la opinión que únicamente los primeros corresponden a un sistema opt-in mientras que los segundos se acercan más a un sistema opt-out.

\section{V.A. Mecanismos de aceptación previa consistentes con un sistema opt-in.}

Los "mecanismos de aceptación previa" citados en el Dictamen 2/2010, fueron descritos en mayor detalle por Las Guías AEPD en un intento por guiar a los proveedores de redes de publicidad de forma que dieran cumplimiento a la normativa. Explican un sistema de-

68 ADSUARA VARELA, B., "El consentimiento", en PIÑAR MAÑAS, J.L., (Dir.) coord. por ÁLVAREZ CARO, M., RECIO GAYO, M., Reglamento general de protección de datos. Hacia un nuevo modelo europeo de privacidad, Reus, Zaragoza, 2016, pág.156.

69 Dictamen 2/2010, apartado 4.1.3, pág. 18.

70 Dictamen 2/2010, apartado 4.1.3, pág. 18. 
nominado "formato de información por capas" que consistente en esencia, en mostrar la información pertinente en la pantalla del usuario de forma sencilla, accesible e interactiva, a la vez que la petición del consentimiento mediante mensajes estructurados entre sí y distribuidos en dos capas. Nos basamos en La Guía AEPD 2019 para explicar los "mecanismos de aceptación previa" consistentes con este formato dada la similitud entre ambas y puesto que la segunda, fruto de la entrada en vigor del RGPD aporta algunas novedades, especialmente en lo relativo a la necesidad de que el consentimiento se dé de forma explícita.

Respecto a la primera capa, ésta ha de estar diseñada para permitir que la información sea perfectamente visible para el usuario a través de un mensaje inicial en pantalla que aparece al acceder a una página web. Éste debe contener la información esencial, es decir, una advertencia de que la página utiliza cookies. Además, debe contener información relativa a todas las finalidades del tratamiento de los datos recabados, si los cookies son sólo del editor responsable de la web (cookies propios), o también de terceros asociados a él. A su vez debe contener un enlace visible que indique el acceso a una segunda capa donde se contiene información específica sobre los cookies y un panel para configuración de los mismos. Esta primera capa también puede incluir, aparte del enlace anterior dos botones que permitan aceptar todos los cookies o rechazarlos todos ${ }^{71}$. En cualquier caso, los mensajes que indiquen "si continua navegando entendemos que acepta su uso" no resultan válidos pues no constituyen la aceptación explícita de los cookies.

En la segunda capa aparte del panel de configuración, también debería figurar la información mínima necesaria para cumplir con el requisito del consentimiento informado. En este sentido, y de acuerdo con las Directrices 05/2020 se debería incluir asimismo la identidad del controlador o responsable ${ }^{72}$, la finalidad de cada uno de los tratamientos que se pretende hacer ${ }^{73}$, los tipos de datos que se van

71 La Guía de 2019 también indica que podrá disponerse un único botón para aceptar todos los cookies. Nosotros no coincidimos pues se está guiando al usuario a que acepte todos los cookies sin darle la misma posibilidad de rechazarlos, cosa que únicamente podrá hacer accediendo al enlace de la segunda capa. Entendemos que en estas circunstancias la elección no sería libre, pág. 20.

72 Vid. Artículo 13 del RGPD y el CDO 42 RGPD: Para que el consentimiento sea informado, el interesado debe conocer como mínimo la identidad del responsable del tratamiento.

73 Vid. Artículo 13 del RGPD y el CDO 42 RGPD: Para que el consentimiento sea informado, el interesado debe conocer como mínimo la identidad del responsable del tratamiento y los fines del tratamiento a los cuales están destinados los datos personales.

(C) UNED. Revista de Derecho UNED, núm. 27, 2021 
a recoger y utilizar ${ }^{74}$, la existencia del derecho a retirar el consentimiento ${ }^{75}$, el periodo de conservación de los datos ${ }^{76}$, información sobre el uso de los datos para decisiones automatizadas y la creación de perfiles de conformidad con el art. 22.2, c) RGPD $^{77}$ cuando sea pertinente, e información sobre los posibles riesgos de transferencia de datos debido a la ausencia de una decisión de adecuación y de garantías adecuadas, tal y como se describen en el art. $46 \mathrm{RGPD}^{78}$.

A nuestro parecer el formato más claro para el panel de configuración es el de disponer casillas ${ }^{79}$ con la información específica respecto a la denominación y finalidad de los cookies de manera que el usuario tenga la oportunidad de tomar una decisión libre e informada sobre cada tipo de cookie (denominación y finalidad) de forma clara y sencilla. La petición del consentimiento ha de hacerse a través de un sistema "granular" que permita disociar las finalidades estableciendo tantas solicitudes como finalidades del tratamiento de los datos recabados por los cookies ${ }^{80}$. Las casillas no deberían estar ya marcadas ${ }^{81}$ para aceptar los cookies (o las finali-

74 Vid. Opinión 15/2011 sobre la definición del consentimiento (WP 187), págs.19-20.

75 Vid. Art. 7.3 RGPD que establece que el interesado tendrá derecho a retirar su consentimiento en cualquier momento...Antes de dar su consentimiento, el interesado será informado de ello.

76 Vid. art.13.2.a RGPD: la información necesaria para garantizar un tratamiento de datos leal y transparente incluye el plazo durante el cual se conservarán los datos personales o, cuando no sea posible, los criterios utilizados para determinar este plazo.

77 Directrices sobre decisiones individuales automatizadas y elaboración de perfiles a los efectos del Reglamento 2016/679 del Grupo de Trabajo sobre protección de datos del artículo 29, adoptadas el 3 de octubre de 2017. Revisadas por última vez y adoptadas el 6 de febrero de 2018. 17/ES WP251rev.01, pág. 20 en adelante.

78 De conformidad con al artículo 49.1 a) RGPD que requiere, en este caso el consentimiento explícito en ausencia de las garantías descritas por el art. 46 RGPD.

79 Vid. CDO 32 RGPD que indica como las casillas como una de los diferentes modos de otorgar el consentimiento. Esta podrá consistir en una declaración por escrito, inclusive por medios electrónicos, o una declaración verbal. Esto podría incluir marcar una casilla de un sitio web en internet, escoger parámetros técnicos para la utilización de servicios de la sociedad de la información, o cualquier otra declaración o conducta que indique claramente en este contexto que el interesado acepta la propuesta de tratamiento de sus datos personales.

80 Vid. CDO 32 RGPD que indica que el consentimiento debe darse para todas las actividades de tratamiento realizadas con el mismo o los mismos fines. Cuando el tratamiento tenga varios fines, debe darse el consentimiento para todos ellos.

Vid. CDO 42 RGPD: Para que el consentimiento sea informado, el interesado debe conocer... los fines del tratamiento a los cuales están destinados los datos personales.

81 Vid. CDO 32 RGPD que indica que el silencio, las casillas ya marcadas o la inacción no deben constituir consentimiento. Entendemos sin embargo que las casillas correspondientes a cookies exentos si pueden estar ya marcadas puesto que no requieren el consentimiento del usuario. 
dades del tratamiento), de forma que resulte necesario que el usuario manifieste su consentimiento procediendo al marcado. De forma simultánea se podrían disponer tres botones que indicarían que se aceptan todos los cookies, que se rechazan todos (salvo los exentos) o que se guarda la configuración establecida por el usuario $^{82}$. Consideramos de vital importancia que los tres botones tengan el mismo diseño de cara a no inducir al usuario a seleccionar uno en concreto lo cual determinaría como ya se ha establecido que el consentimiento no fuese válido. En cualquier caso, la visualización de la segunda capa únicamente debería desaparecer una vez realizada la acción que determine la configuración de los cookies.

Otra condición que determina la validez del consentimiento es aquélla relativa al modo en que se presenta información (art. 7.2 RGPD). Ésta ha de distinguirse claramente de los demás asuntos, ser inteligible, y de fácil acceso. La información necesaria para que el usuario pueda adoptar una decisión informada no debe estar alojada en lugares de difícil acceso. Además, las solicitudes han de utilizar un lenguaje claro y sencillo, entendiéndose que la información ha de ser de comprensible para un ciudadano medio ${ }^{83}$ descartándose la posibilidad de que los responsables o controladores dispongan políticas de privacidad extensas, con lenguaje complejo, y plagadas de terminología técnica y jurídica.

Los mecanismos de aceptación previa basados en el formato de información por capas son por tanto una opción apropiada pues aparte de permitir la granularidad o disociación de las solicitudes, presentar la información de forma precisa, completa y comprensible si se diseñan de forma que sean claras y concisas y no perturben el uso del servicio para el que se presta (CDO 32 RGPD). Otros avisos de cookies, tales como los que se mencionan a continuación consideramos no resultan aptos para obtener el consentimiento de forma válida conforme al art. 5.3.

\section{V.B. Mecanismos que no constituyen un verdadero sistema opt-in}

En contraste con los mecanismos de aceptación consistentes con un "formato por capas", podemos distinguir que considera-

82 Vid. CDO 32 RGPD que indica que el consentimiento debe darse mediante un acto afirmativo claro.

83 Vid. Directrices 05/2020 sobre el consentimiento en el sentido del reglamento 2016/679. Versión 1.1, adoptado el 4 de mayo de 2020, por el Comité Europeo de protección de Datos, apartado 67, pág. 16. 
mos aquéllos que consideramos no cumplen con el sistema opt-in, o que sólo lo hacen el algunos casos muy limitados. Nos encontramos pues, con avisos de cookies diseñados en cumplimiento de la normativa anterior, y con aquéllos que en cumplimiento a la normativa actual remiten bien a sistemas de exclusión voluntaria, bien a la configuración de los parámetros de privacidad del navegador como herramienta para otorgar el consentimiento.

Los primeros ya se ha dicho son consistentes con un sistema optout, y podrían ser denominados "mecanismos de exclusión" por cuanto se limitan a informar al usuario de la inminente instalación de cookies en sus terminales y posterior tratamiento de sus datos $^{84}$. A pesar de aludir al derecho del usuario a ejercer su oposición o exclusión, ésto sólo es posible en un momento posterior a la instalación de los cookies.

Conforme a la norma actual, los "sistemas de exclusión voluntaria" son aquéllos que permiten al usuario optar por no recibir publicidad comportamental cuando acceden a una página web a través de la cual deben entrar en el sitio de internet del proveedor de la red de publicidad e indicar que no desean recibir publicidad comportamental ${ }^{85}$. A priori, estos mecanismos no explicitan, el consentimiento del usuario puesto que requieren que éste realice una acción positiva optar por rechazar este tipo de cookies puesto que están diseñados por defecto para que se instalen. Sólo cuando el usuario sea conocedor de lo que supone la publicidad comportamental, sepa cómo "desactivarla" y decida conscientemente aceptarla, se puede presumir que su falta de acción constituye un acto consciente de no exclusión y por tanto puede inferirse un consentimiento si bien implícito, válido ${ }^{86}$. En consecuencia, en la mayoría de los casos, el usuario no revoca expresamente su consentimiento porque desconoce a la vez que sus datos van a ser tratados y cómo ejercer su derecho de exclusión ${ }^{87}$. Su consentimiento se da por hecho de forma implícita pero no puede considerarse como válidamente otorgado. Por ello, el Dictamen 2/2010 indicaba que estos mecanismos necesariamente debían requerir del usuario una acción explícita que indicase su disponibilidad a aceptar los cookies y el ulterior control de su comportamiento durante la navegación con objeto de recibir publicidad a medida ${ }^{88}$ para que el consentimiento sea fundamentado y vá-

\footnotetext{
84 Dictamen $2 / 2010$, pág. 26

85 Dictamen $2 / 2010$, pág. 17

86 Dictamen 2/2010, pág. 17.

87 Dictamen 2/2010, apartado 6.4, pág. 26.

88 Dictamen 2/2010, apartado 6.4, pág. 26.
} 
lido, por lo que instaba a que fueran sustituidos por mecanismos de aceptación previos.

Los avisos de cookies que remiten al usuario a la configuración de los parámetros de privacidad del navegador o de otra aplicación como mecanismo para otorgar el consentimiento se basan en el CDO $66^{89}$ de la Directiva 2009/136/CE. Esta posibilidad no constituye una excepción a la aplicación del art. 5.3 pues lo que indica es que el consentimiento puede darse de diferentes modos cuando sea técnicamente posible y eficaz y de acuerdo con los demás requisitos pertinentes del consentimiento válido ${ }^{90}$. Sin embargo, pese a la creencia de la Directiva de que fuesen capaces de ser herramientas válidas para prestar el consentimiento, éstos sólo pueden expresar consentimiento en circunstancias muy limitadas puesto que, en la práctica, en la mayoría de los casos, los cookies se instalan sin el consentimiento previo del usuario. A modo de ejemplo, sólo cuando el buscador esté configurado por defecto para rechazar todos los cookies y el usuario haya cambiado las configuraciones para que acepten explícitamente los cookies ${ }^{91}$, y siempre que el usuario haya recibido información completa del nombre del responsable del tratamiento de los datos, de los fines del tratamiento y de los datos que se recogen ${ }^{92}$ el consentimiento podrá ser considerado como válido. Por ello, sería necesario que el buscador sólo o en combinación con otros medios, transmitiera información clara, completa y perfectamente visible sobre el tratamiento de los datos ${ }^{93}$.

Por el contrario, como ocurre en muchos casos, si los buscadores están configurados por defecto para aceptar todos los cookies y el usuario no cambia esta configuración antes de dar su consentimiento, éstos se instalarán automáticamente y únicamente podrá ejercer su derecho de oposición o exclusión. Además, en muchos casos estos avisos de cookies se limitan a informar de que si el usuario continúa navegando se entiende que ha prestado su consentimiento.

89 CDO 66 Directiva 2009/136/CE: Cuando sea técnicamente posible y eficaz, de conformidad con las disposiciones pertinentes de la Directiva 95/46/CE, el consentimiento del usuario para aceptar el tratamiento de los datos puede facilitarse mediante el uso de los parámetros adecuados del navegador o de otra aplicación.

90 Dictamen 2/2010, pág. 15.

91 Dictamen 2/2010, apartado 6.4, pág. 26.

92 Esta posibilidad figura como parte del art. 22.2 segundo párrafo LSSI-CE que indica que "cuando sea técnicamente posible y eficaz, el consentimiento del destinatario para aceptar el tratamiento de los datos podrá facilitarse mediante el uso de los parámetros adecuados del navegador o de otras aplicaciones, siempre que aquél deba proceder a su configuración durante su instalación o actualización mediante una acción expresa a tal efecto".

93 Dictamen 2/2010, pág. 26. 
En consecuencia, no sólo estamos ante mecanismos que no son expresión válida del consentimiento, sino que constituyen en realidad un sistema opt-out, "disfrazado" bajo la apariencia de opt-in al no ajustarse a la norma.

La utilización, tanto de sistemas de exclusión voluntaria, como los basados en el CDO 66 de la Directiva 2009/136/CE, siguen siendo una práctica habitual. En ambos casos se ha visto rara vez son capaces de expresar el consentimiento del usuario de forma válida. En consecuencia, consideramos se alejan del sistema opt-in y que constituyen o se acercan a un sistema opt-out,

\section{REVISIÓN DE LA DIRECTIVA 2002/58/CE Y PROPUESTA DE UN NUEVO REGLAMENTO}

La aprobación del RGPD generó la necesidad de modificar la Directiva 2002/58/CE para aclarar la relación entre ambos estableciéndose que debía ser revisada tras la adopción del RGPD ${ }^{94}$. Los casi veinte años de vigencia, aun habiendo sido modificada, unida a los avances tecnológicos surgidos durante este periodo que originaban nuevos supuestos que se distancian de su alcance, también apuntaban a esta necesidad. La evidencia fruto de la revisión de la Directiva 2002/58CE llevada a cabo por la Comisión indica una falta de eficacia del art. 5.3 y pone de manifiesto supuestos incumplimiento. Esta revisión que se produjo con anterioridad a la entrada en vigor del RGPD a su vez refrenda en parte las opiniones expresadas por el extinto GT29. La jurisprudencia del Tribunal de Justicia en los asuntos C-40/17 Fashion ID, y C-672/17 Planet49 también muestra la necesidad de modificar la normativa vigente al poner en evidencia prácticas que no se ajustan a la norma.

Ya desde 2017 contamos con una Propuesta de Reglamento sobre la privacidad y las comunicaciones electrónicas ${ }^{95}$, (en adelante ePrivacy Regulation), para sustituir a la Directiva 2002/58/CE que si bien prevé las disposiciones contenidas en el RGPD, es anterior a

94 Vid. CDO 173 del RGPD: Para aclarar la relación entre el presente Reglamento y la Directiva 2002/58/CE, esta última debe ser modificada en consecuencia. Una vez que se adopte el presente Reglamento, debe revisarse la Directiva 2002/58/CE, en particular con objeto de garantizar la coherencia con el presente Reglamento.

95 Propuesta de Reglamento del Parlamento Europeo y del Consejo sobre el respeto de la vida privada y la protección de los datos personales en el sector de las comunicaciones electrónicas y por el que se deroga la Directiva 2002/58/CE (Reglamento sobre la privacidad y las comunicaciones electrónicas). Bruselas, 10.1.2017 $\operatorname{COM}(2017) 10$ final 2017/0003 (COD). 
su entrada en vigor. Las Declaraciones del EDGP emitidas con posterioridad a la entrada en vigor del RGPD, emplazan al legislador a acometer dicha reforma a la mayor brevedad. Procede por tanto explicar cuáles son las carencias de la normativa actual, la reforma que se propone, y las propuestas de mejora al futuro ePrivacy Regulation que está llamado a sustituir a la Directiva 2002/58/CE.

\section{VI.A. Revisión de la Directiva 2002/58/CE}

La revisión de la Directiva 2002/58/CE ${ }^{96}$ ha determinado, que la aplicación de las normas del consentimiento relativas a la confidencialidad de los terminales, también conocida como "la norma de cookies ${ }^{97 "}$ no resulta enteramente efectiva y no se ha transpuesto de forma homogénea en el territorio de la Unión ${ }^{98}$. No resulta infrecuente encontrarse ante mecanismos de aceptación de cookies que contienen un lenguaje complejo que no permite a los usuarios de internet comprender aquello que aceptan. En algunos casos la instalación de cookies tiene lugar, incluso sin solicitar el consentimiento. Otra práctica comporta la utilización de solicitudes que son inclusivas en exceso por cuanto incluyen o se aplican también a los cookies exentos $^{99}$. La práctica denominada "pared de cookies" que

${ }^{96}$ COMMISSION STAFF WORKING DOCUMENT. Executive Summary of the Ex-post REFIT evaluation of the ePrivacy Directive Accompanying the document Proposal for a Regulation of the European Parliament and of the Council on the protection of privacy and confidentiality in relation to electronic communications and repealing Directive 2002/58/EC ( "the ePrivacy Regulation") Bruselas, 10.1.2017 $\operatorname{SWD}(2017) 6$ final.

97 COMMISSION STAFF WORKING DOCUMENT. Executive Summary of the Ex-post REFIT evaluation of the ePrivacy Directive Accompanying the document Proposal for a Regulation of the European Parliament and of the Council on the protection of privacy and confidentiality in relation to electronic communications and repealing Directive 2002/58/EC ( "the ePrivacy Regulation") Bruselas, 10.1.2017 $\operatorname{SWD}(2017) 5$ final, págs. 23, 74, 86, 87, 90 y 93.

98 De acuerdo con el estudio llevado a cabo por la Monopolkommission, la comisión de vigilancia de monopolios del servicio federal de defensa de la competencia, algunos países como Finlandia o Luxemburgo no adoptaron el sistema optin sino el opt-out basándose en el CDO 66 de la Directiva 2009/136 que indica que las configuraciones de los navegadores podían ser un instrumento válido para otorgar el consentimiento.

Monopolkomission report, 'Competition policy: The challenge of digital markets', 2015, págs. 33-34.

https://www.monopolkommission.de/images/PDF/SG/s68_fulltext_eng.pdf

99 COMMISSION STAFF WORKING DOCUMENT. Executive Summary of the Ex-post REFIT evaluation of the ePrivacy Directive Accompanying the document Proposal for a Regulation of the European Parliament and of the Council on the protection of privacy and confidentiality in relation to electronic communications

(C) UNED. Revista de Derecho UNED, núm. 27, 2021 
consiste en supeditar el acceso a los contenidos de una página web a la aceptación de todos los cookies, supone que los usuarios no tengan capacidad de elegir libremente y tiendan mayoritariamente a prestar su consentimiento ante la tentación de acceder a los contenidos. Estas prácticas y la constante exposición de los usuarios a diferentes solicitudes provocan la llamada "fatiga del consentimiento ${ }^{100 "}$ y frustración, a la vez que afecta negativamente su experiencia de navegación. En respuesta a esta situación la evaluación de la Directiva 2002/58/CE estima la opción de expresar el consentimiento a través de las configuraciones de los buscadores, como procedimiento más sencillo.

\section{VI.B. Jurisprudencia del Tribunal de Justicia de la UE.}

Como ya se ha anticipado existe Jurisprudencia por parte del Tribunal de Justicia, en concreto los asuntos C-40/17 Fashion ID, C-672/17 Planet49 que avalan la necesidad de reforma del sistema. En el asunto C-40/17, Fashion ID una empresa de comercio electrónico dedicada a la venta de artículos de moda insertó el botón (plugin) "Me gusta" de Facebook. Cuando un usuario accedía a la página de Fashion ID en la que figuraba el botón, la información relativa a la Dirección IP del usuario y la secuencia de su navegador, se transfería automáticamente a Facebook. Esto ocurría con independencia tanto de que el usuario hubiera clicado en el botón de "me gusta", como de que tuviera o no cuenta en Facebook. El uso del plug-in permitía a Fashion ID optimizar la publicidad de sus productos al mostrarlos en Facebook ${ }^{101}$.Tanto de la sentencia como de las conclusiones del Abogado General Bobek se desprende que los datos transferidos a Facebook Ireland se utilizaban con fines comerciales propios de esta última ${ }^{102}$.

and repealing Directive 2002/58/EC ( "the ePrivacy Regulation") Bruselas, 10.1.2017 $\operatorname{SWD}(2017) 6$ final, pág. 3.

100 COMMISSION STAFF WORKING DOCUMENT. Executive Summary of the Ex-post REFIT evaluation of the ePrivacy Directive Accompanying the document Proposal for a Regulation of the European Parliament and of the Council on the protection of privacy and confidentiality in relation to electronic communications and repealing Directive 2002/58/EC ( "the ePrivacy Regulation") Bruselas, 10.1.2017 $\operatorname{SWD}(2017) 5$ final, pág. 41

101 Punto 68. Conclusiones del Abogado General SR. MichalBobek presentadas el 19 de diciembre de 2018. Asunto C-40/17. Fashion ID GMbH\& Co. KG c. Verbraucherzentrale $N R W \mathrm{eV}$. Coadyuvantes: Facebook Ireland Limited, LandesbeauftragtefürDatenschutz und InformationsfreiheitNordrhein- Westfalen.

102 Punto 104. Conclusiones del Abogado General SR. MichalBobek presentadas el 19 de diciembre de 2018. Asunto C-40/17. Fashion ID GMbH\& Co. KG con- 
Si bien el asunto tiene por objeto una petición de decisión prejudicial respecto a quién es el responsable del tratamiento de los datos (Fashion ID, Facebook Ireland o ambos), tanto la sentencia como las conclusiones del Abogado abordan la licitud del tratamiento de los datos personales que se transfieren (Dirección IP y secuencia del navegador) y si la obligación de informar al interesado recae sobre Fashion ID, Facebook Ireland. Las conclusiones a las que se llega en ambos documentos concluyen que es Fashion ID quien debe solicitar el consentimiento y no Facebook Ireland (el proveedor del plug-in) puesto que el hecho de que un visitante consulte el sitio web de Fashion ID es lo que desencadena el proceso del tratamiento de los da$\operatorname{tos}^{103}$. Lo mismo se establece respecto de la obligación de información establecida en el art. 10 de la Directiva 95/46/CE ${ }^{104}$. Aun cuando la sentencia no indica explícitamente que Fashion ID esté incumpliendo la obligación de solicitar el consentimiento y el deber de información previos pues no es objeto del asunto, el Abogado General Bobek expone claramente que Fashion ID ha de solicitar el consentimiento al indicar que el consentimiento del interesado obtenido con arreglo al artículo 7, letra a) de la Directiva 95/46 debe darse al operador de la página web en la que se ha insertado el contenido de un tercero. El artículo 10 de la Directiva 95/46 debe interpretarse en el sentido de que la obligación de informar que preceptúa dicha disposición se aplica también a ese operador de la página web. El consentimiento del interesado a que se refiere el al artículo 7, letra a) de la Directiva 95/46 debe prestarse y la información que exige el artículo 10 de la misma debe facilitarse, antes de que los datos sean recabados y transferidos ${ }^{105}$. Dado que la transmisión de los datos y su tratamiento posterior se producía sin que el usuario hubiera prestado su consenti-

tra Verbraucherzentrale NRW eV. coadyuvantes: Facebook IrelandLimited, LandesbeauftragtefürDatenschutzundInformationsfreiheitNordrhein-Westfalen y punto 27 de la Sentencia de 29 de julio de 2019, Fashion ID GmbH\& Co.KG c. Verbraucherzentrale NRW eV, Asunto C-40/17, ECLI:EU:C:2019:629

103 Punto 102. Sentencia de 29 de julio de 2019, Fashion ID GmbH\& Co.KG c. Verbraucherzentrale NRW eV, Asunto C-40/17, ECLI:EU:C:2019:629 y punto 141, yconclusiones del Abogado General SR. MichalBobek presentadas el 19 de diciembre de 2018. Asunto C-40/17. Fashion ID GMbH\& Co. KG contra Verbraucherzentrale NRW eV. coadyuvantes: Facebook IrelandLimited, LandesbeauftragtefürDatenschutzundInformationsfreiheitNordrhein-Westfalen.

104 Punto 103. Sentencia de 29 de julio de 2019, Fashion ID GmbH\& Co.KG c. Verbraucherzentrale NRW eV, Asunto C-40/17, ECLI:EU:C:2019:629

Punto 141. Conclusiones del Abogado General Sr. MichalBobek presentadas el 19 de diciembre de 2018. Asunto C-40/17. Fashion ID GMbH\& Co. KG contra Verbraucherzentrale NRW eV. coadyuvantes: Facebook IrelandLimited, LandesbeauftragtefürDatenschutzundInformationsfreiheitNordrhein-Westfalen.

105 Vid. Último párrafo de las Conclusiones del Abogado General Sr. Michal Bobek presentadas el 19 de diciembre de 2018. Asunto C-40/17. Fashion ID GMbH\&

(C) UNED. Revista de Derecho UNED, núm. 27, 2021 
miento ni tuviera conocimiento de ello, no se daba cumplimiento a los artículos 5.3, de la Directiva 2002/58/CE, y los artículos 7 a), y 10 de la Directiva 95/46/CE.

Mayor importancia si cabe cobra la sentencia en el asunto C-672/17 Planet49 puesto que tiene por objeto la interpretación del art. 5.3 de la Directiva 2002/58/CE así como los preceptos relativos al consentimiento tanto en la Directiva 95/46 como en el RGPD. Esta doble interpretación se imponía puesto que la cuestión prejudicial se planteaba durante la vigencia de la primera pero la sentencia se produce con posterioridad a su derogación y durante la vigencia del RGPD ${ }^{106}$. Conforme a los hechos relatados, para participar en un juego dotado con un premio organizado por la empresa Planet49, un internauta debía marcar o quitar la marca de dos casillas de verificación antes de poder pulsar el botón de participación en el juego. La primera casilla obligaba al usuario a aceptar que una serie de empresas se pusieran en contacto con él para enviarle ofertas promocionales, y aunque no estaba inicialmente marcada, el internauta no podía participar salvo que la marcase antes de pulsar el botón de participación. Esta casilla de verificación no estaba relacionada con la instalación de cookies sino con datos personales como la dirección de correo electrónico o número de teléfono móvil. La segunda casilla estaba marcada por defecto para aceptar la instalación de cookies en su ordenador. Estos cookies permitirían analizar el comportamiento de navegación del participante y uso de las páginas web de Planet49 y sus socios para enviar publicidad específica o comportamental al participante.

Ante este caso, el Abogado General Szpunar determina que no existe un consentimiento efectivo por varios motivos. El primero y en cuanto a la segunda casilla indica que el hecho de que esté ya marcada para aceptar los cookies obliga al usuario a comportarse de modo activo para retirar su consentimiento en lugar de para otorgarlo. En este sentido, si el usuario no retira la marca es prácticamente imposible determinar de forma objetiva si ha dado su consentimiento sobre la base de una decisión libre e informada ${ }^{107}$. Por el contrario, si

Co. KG contra Verbraucherzentrale NRW eV. coadyuvantes: Facebook Ireland Limited, LandesbeauftragtefürDatenschutzundInformationsfreiheitNordrhein-Westfalen.

${ }^{106}$ En los puntos 42, 45, 46 y 47 De las Conclusiones del Abogado General Szpunar, aclara que son dos los instrumentos jurídicos aplicables al litigio. La Directiva 95/46/CE es de aplicación a las situaciones anteriores a su derogación puesto que el litigio se planteó mediante resolución de 5 de octubre de 2017 mientras ésta estaba vigente, y el RGPD a las situaciones posteriores al 25 de mayo de 2018 puesto que la sentencia se dictó el 1 de octubre de 2019.

107 Punto 88 de las conclusiones del Abogado General Szpuner. 
tiene que marcar una casilla para dar el consentimiento a la instalación de cookies y el tratamiento de los datos la afirmación de que la decisión es libre e informada es mucho más probable. En segundo lugar, pulsar el botón de participación implica manifestar de forma simultánea dos voluntades distintas, una la participación en el juego y otra, la prestación o no del consentimiento a la instalación de los cookies de publicidad comportamental. Ambas han de manifestarse de forma separada y no a través del mismo botón ya que la prestación de un servicio no debería supeditarse al consentimiento de los cookies. Aunque es cierto que se puede quitar la marca del consentimiento, el abogado duda que este paquete de manifestaciones de voluntad sea conforme al concepto del consentimiento en el sentido de la Directiva 95/46/CE. Sin embargo a la luz del RGPD queda claro que las manifestaciones de voluntades han de darse de forma separada para las distintas operaciones de tratamiento de datos personales (los recabados mediante la primera casilla y los correspondientes a los cookies de la segunda) conforme a su CDO $43^{108}$.

En sus conclusiones, el Abogado Szpunar va más allá al sostener que los requisitos relativos a la manifestación del consentimiento previstos en la Directiva 95/46/CE son los mismos que los establecidos en el RGPD. En ambos casos la manifestación de voluntad ha de ser libre, específica e informada. Como ya se ha indicado, el RGPD añade la necesidad de que ésta sea inequívoca y por tanto se realice a través de una declaración o una clara acción afirmativa. El Abogado indica que en el caso de la Directiva 95/46/CE también ha de cumplirse este requisito adicional puesto que la necesidad de que exista una manifestación de voluntad indica claramente un comportamiento activo y no pasivo. Además, conforme al art. 7 a) de la Directiva 95/46/CE se establece que el consentimiento ha de ser inequívoco contribuyendo a reforzar esta opinión puesto que para evitar la ambigüedad el comportamiento ha de ser activo en oposición a pasivo $^{109}$. Todas las opiniones del Abogado Szpunar respecto a los requisitos del consentimiento y su validez para la casilla segunda fueron refrendadas por la sentencia que declaró que, tanto si procediera la aplicación del art.5.3 de la Directiva 2002/58/CE de forma conjunta con la Directiva 96/46/CE o con el RGPD, el consentimiento al que hacen referencia no se presta de manera válida cuando los coo-

108 El CDO 43 del RGPD establece que se presume que el consentimiento no se ha dado libremente cuando no permita autorizar por separado las distintas operaciones de tratamiento de datos personales pese a ser adecuado en el caso concreto, o cuando el cumplimiento de un contrato, incluida la prestación de un servicio, sea dependiente del consentimiento, aún cuando este no sea necesario para dicho cumplimiento.

109 Punto 60 de las Conclusiones del Abogado Szpuner. 
kies se autorizan mediante una casilla marcada por defecto en la que el usuario debe retirar la marca en caso de no prestar su consentimiento, poniéndose en evidencia la falta de cumplimiento del art. 5.3 de la Directiva 2002/58/CE.

Ante la evidencia de la falta de cumplimiento o de eficacia del art. 5.3 de la Directiva 2002/58/CE y su dudosa aplicación a nuevas técnicas de rastreo ${ }^{110}$, la propuesta del futuro ePrivacy Regulation clarifica y simplifica la norma relativa al consentimiento para el uso de los cookies estableciendo la posibilidad de expresar el consentimiento a través de los parámetros técnicos de los navegadores. Amplia el instrumento jurídico para incluir otros identificadores y nuevos servicios y comunicaciones electrónicas que no formaban parte de su ámbito de aplicación a los antes mencionados servicios de transmisión libre. La generalización de estos servicios desde las modificaciones introducidas por la Directiva 2009/136/CE confirma la necesidad de extender la protección de la confidencialidad de las comunicaciones de los usuarios. Esta situación hizo que el CEPD ${ }^{111}$, que revisó la Propuesta ePrivacy Regulation, estableciera la necesidad de proceder a la aprobación del Reglamento lo antes posible ${ }^{112}$, no sin antes proponer enmiendas.

110 COMMISSION STAFF WORKING DOCUMENT. Executive Summary of the Ex-post REFIT evaluation of the ePrivacy Directive Accompanying the document Proposal for a Regulation of the European Parliament and of the Council on the protection of privacy and confidentiality in relation to electronic communications and repealing Directive 2002/58/EC ( "the ePrivacy Regulation") Bruselas, 10.1.2017 $\operatorname{SWD}(2017) 6$ final, pág. 69.

Plantea si el artículo 5.3 de la directiva 2002/58/CE resulta de aplicación a nuevas técnicas que utilizan los identificadores de los terminales para fines de rastreo como el rastro Wi-Fi o el rastro de la huella digital (fingerprinting). Estas técnicas han de someterse al RGPD pero se plantean dudas respecto a que el artículo 5.3 pueda ser de aplicación.

Opinión 9/2014 del Grupo de trabajo de protección de datos del artículo 29 sobre la aplicación de la Directiva 2002/58/EC a la huella digital de los dispositivos, adoptada el 25 de noviembre de 2014. 14/ENWP 224, pág. 3. De acuerdo con la Opinión del GT éstas tecnologías si quedarían sometidas al artículo 5.3 de la Directiva 2002/58/CE.

${ }^{111}$ Declaración del Comité Europeo de Protección de Datos relativa a la revisión del Reglamento sobre la privacidad y las comunicaciones electrónicas y su repercusión en la protección de las personas en lo que respecta a la privacidad y la confidencialidad de sus comunicaciones. 25 de mayo de 2018. https://edpb.europa.eu/ sites/edpb/files/files/file1/edpb_statement_on_eprivacy_es_0.pdf

112 En su declaración de 25 de mayo de 2018, el CEPD también establecía, junto con la necesidad de proteger a los usuarios que se creasen unas condiciones de competencia equitativas para los proveedores de servicios de comunicación electrónica y de servicios de función equivalente. 


\section{PROPUESTA DE REGLAMENTO: ePRIVACY REGULATION.}

La nueva regulación sobre cookies que se encuentra en el art. 8 de la Propuesta ePrivacy Regulation relativa a la "protección de la información almacenada en los equipos terminales de los usuarios finales y relativa a dichos equipos" se desmarca del antiguo art. 5 referido a la confidencialidad de las comunicaciones ${ }^{113}$ dado en la redacción vigente. Se establece así una categoría separada y diferenciada de éstas que englobaría tanto los cookies como otras tecnologías que permiten hacer uso de los terminales para obtener datos concretos ampliando su ámbito de aplicación a supuestos no contemplados en la normativa anterior. La nueva redacción se refiere al uso de las capacidades de tratamiento y almacenamiento de los equipos terminales y la recopilación de información del equipo terminal de los usuarios finales, incluida la relativa a su soporte físico y lógico ${ }^{114}$, eliminándose la alusión anterior al acceso a la información almacenada en el terminal del usuario. La nueva redacción se justifica puesto que permite la aplicación de este artículo a nuevas tecnologías diferentes de los cookies que pueden utilizarse para obtener datos utilizados en la creación de perfiles con fines de publicidad comportamental. Mantiene la prohibición general de acceso a datos de los terminales a la vez que las excepciones a esta prohibición, tanto cuando el usuario haya prestado su consentimiento, como en los dos supuestos de exención contemplados en la normativa anterior, ampliándose a un supuesto adicional cuando los datos sean necesarios para medir la audiencia en la web, siempre que esa medición corra a cargo del proveedor del servicio de la sociedad de la información solicitado por el usuario final por considerarse que éstos entrañan pocos riesgos para la privacidad de los usuarios ${ }^{115}$.

113 En el art. 5 se establece que todas las comunicaciones electrónicas serán confidenciales y se prohíbe cualquier interferencia a cuyo efecto aporta ejemplos como el seguimiento, análisis u otros tipos de interceptación, vigilancia o tratamiento de comunicaciones electrónicas.

114 Esta redacción sustituye a la dada por el artículo 5.3 de la Directiva 2002/58/ CE que se refería al almacenamiento de información, o la obtención de acceso a la información ya almacenada, en el equipo terminal de un abonado o usuario, sustituyéndose el acceso a la información del terminal por las capacidades de tratamiento, almacenamiento y recopilación de información del terminal incluyéndose información relativa al soporte físico y lógico de los terminales. Se incluyen así nuevas formas de acceder a datos como la huella digital que utiliza tecnologías diferentes a los cookies y que permite la elaboración de perfiles por parte del responsable del tratamiento.

115 Esta nueva excepción ya fue sugerida por el GT29 en el apartado 4.3 de su Dictamen 4/2012 al indicar que considera que los cookies de medición estadística de audiencia o cookies para análisis propios, probablemente no supongan un riesgo para la privacidad en el caso de que se limiten estrictamente a fines estadísticos agregados propios y de que sean utilizados por sitios web que ya ofrecen información

(C) UNED. Revista de Derecho UNED, núm. 27, 2021 
$\mathrm{El}$ art. 8.2 se refiere a la información emitida por un equipo terminal para poder conectarse a otro dispositivo o a un equipo de red. Inferimos que se refiere a la transmisión de comunicaciones máquina a máquina ${ }^{116}$ o el "internet de las cosas ${ }^{117 "}$ (denominados en ingles The Internet ofThings - IoT), y el WiFi Tracking ${ }^{118}$ y su inclusión correspondería a supuesto no cubierto por los anteriores arts. 5.1, 6 y 9 de la Directiva 2002/58/CE. Estos supuestos de transmisiones de comunicaciones electrónicas no utilizan cookies pero pueden suponer un almacenamiento de datos que pueden tener la consideración de datos personales ${ }^{119}$. Por su parte, el art. 8.3 se refiere al modo en que

clara sobre estos cookies conforme a su política de privacidad, así como garantías adecuadas de privacidad.

116 El CDO 12 de la Propuesta del Reglamento sobre la privacidad indica que Los dispositivos y máquinas conectados se comunican cada vez más entre sí mediante redes de comunicaciones electrónicas (internet de las cosas). La transmisión de comunicaciones de máquina a máquina comporta el transporte de señales a través de una red $y$, por ende, constituye generalmente un servicio de comunicaciones electrónicas.

117 MOISÉS BARRIO, A. Internet de las cosas. Editorial Reus. 2018. Prólogo. El Internet de las Cosas se refiere a sistemas que implican la adquisición de datos de sensores y la entrega de órdenes a dispositivos que interactúan o forman parte del mundo real. También reconocen eventos y cambios y pueden reaccionar de forma rápida y autónoma. Este término se equipara a menudo a electrodomésticos y bienes de consumo como las ropas tecnológicas o los coches inteligentes.

118 COMMISSION STAFF WORKING DOCUMENT. Executive Summary of the Ex-post REFIT evaluation of the ePrivacy Directive Accompanying the document Proposal for a Regulation of the European Parliament and of the Council on the protection of privacy and confidentiality in relation to electronic communications and repealing Directive 2002/58/EC ( "the ePrivacy Regulation") Bruselas, 10.1.2017 SWD(2017) 6 final, págs. 36 y 37. Cuando el usuario tiene conectado el acceso WiFi en su terminal, éste emite de forma continua un identificador único llamado dirección MAC (Media Access Control). Estos pueden ser utilizados para contar personas, rastrear y seguir sus movimientos dentro de un área de emisión de una red WiFi privada como la de un aeropuerto o centro comercial. Esto incluye el seguimiento de los trayectos que realizan, así como los tiempos que permanecen en distintos lugares.

${ }_{119}$ La prohibición de recopilar información establecida en el art. 8.2 no es en realidad una prohibición puesto que a continuación se establecen diferentes supuestos ante los que no opera tal prohibición. La primera exención está justificada como necesaria pues se prevé para cuando se lleve a cabo con el fin exclusivo de establecer una conexión y solamente durante el tiempo necesario para ello. Sin embargo, la segunda únicamente queda ligada al deber de informar al usuario a través de una advertencia clara y destacada que informe, como minimo, de las modalidades de recopilación, su finalidad, las personas responsables de ella y la información restante requerida. En el caso de que éstos tengan la consideración de datos de carácter personal sería el art. 13 del RGPD el que establecería la necesidad de aportar información adicional a través de una advertencia informativa clara y destacada, es decir un aviso, se une a cualquier medida que pueda adoptar el usuario final del equipo terminal para interrumpir o reducir al mínimo la recopilación, entendiéndose como tales las posibles configuraciones de privacidad que pueda establecer el usuario en su terminal. La recopilación de esta información queda supeditada a la obligación 
ha de facilitarse la información en las advertencias del artículo 8.2 b) y por tanto no es el caso de los cookies ${ }^{120}$.

El art. 9 de la Propuesta RP relativo al consentimiento remite de forma expresa, como no podía ser de otro modo, tanto a la definición dada por el RGPD como las condiciones relativas al consentimiento contenidas en sus arts. 4, apartado 11 y 7 . Se incluye en este precepto un apartado segundo que determina la posibilidad de que el usuario exprese su consentimiento, cuando fuera técnicamente posible y factible mediante la configuración técnica adecuada de una aplicación informática que permita acceder a Internet. Esta posibilidad, anunciada en el CDO 66 de la Directiva 2009/136/CE, irrumpe en la normativa y resulta aplicable a los supuestos cubiertos por el art. $8.1 \mathrm{~b}$ ) y, por tanto, a los cookies. Conviene dejar claro que no elimina la utilización de declaraciones o mecanismos de aceptación previos pero estamos seguros de que su uso se reducirá en gran medida. Cuestión distinta es si logrará que el consentimiento se preste válidamente tal y como ya expuso el GT29121 en la descripción que hizo al efecto.

La información y a las opciones de configuración de privacidad que han de proporcionarse para que el consentimiento se considere válidamente otorgado están contenidas en el art. 10 de la Propuesta ePrivacy Regulation. Éste se refiere a los programas informáticos comercializados (como por ejemplo los navegadores) que permiten comunicaciones electrónicas ${ }^{122}$, incluida la recuperación y presentación de información de Internet. Estos programas han de ofrecer la posibilidad de impedir a terceros almacenar información sobre el equipo terminal del usuario así como el tratamiento de la información ya almacenada en él. Al iniciarse la instalación,

del responsable y el encargado del tratamiento de los datos de aplicar las medidas técnicas y organizativas adecuadas que garantizar un nivel de seguridad apropiado en relación con los riesgos, según lo establecido en el artículo 32 del RGPD que establece las medidas de seguridad en el tratamiento de los datos estableciendo la obligación del responsable y del encargado del tratamiento de establecer medidas como la seudonimización y el cifrado de los datos entre otras.

120 Ésta podrá proporcionarse en combinación con el uso de iconos normalizados que ofrezcan, de forma fácilmente visible, inteligible y claramente legible, una adecuada visión de conjunto. Tanto la información que han de contener estos iconos normalizados como los procedimientos para suministrarlos podrán ser determinados por Comisión mediante la adopción de actos delegados (art. 25 Propuesta ePrivacy Regulation).

121 Dictamen 2/2010, págs. 15 -16.

122 Puesto que se hace referencia a la diferencia que existe entre la transmisión de las comunicaciones interpersonales y las comunicaciones máquina a máquina por lo que se deduce que se refiere a ambas. 
deben informar a los usuarios acerca de las opciones de confidencialidad, no pudiendo continuarse con la instalación hasta que el usuario haya configurado dichas opciones y prestado su consentimiento para establecer la configuración elegida. El RGPD en su art. 25 , establece el principio de protección de datos desde el diseño y por defecto. El Supervisor Europeo de protección de datos (en adelante SEPD) recomienda modificar la redacción del art. 10 de la Propuesta ePrivacy Regulation para reforzar la protección estableciendo una configuración protectora de privacidad por defecto ${ }^{123}$, e incluir en el precepto la última oración del CDO 24 de la propia Propuesta ePrivacy Regulation para que los usuarios tengan la posibilidad de modificar los parámetros de privacidad en cualquier momento durante la utilización para excluir o aceptar determinados sitios web o especificar en qué sitios web aceptan siempre o no aceptan nunca cookies de terceros.

No cabe duda que un sistema basado en la privacidad por defecto aumentaría el grado de protección, pero a la vez probablemente resultaría negativo para los proveedores de publicidad. Quizás por ello, el artículo 10 alude a "la configuración elegida" deduciéndose la posibilidad de elegir entre diferentes opciones tal y como se desprende del CDO 23 de la Propuesta ePrivacy Regulation. Distingue tres opciones de configuración de más a menos protectoras: no aceptar nunca los cookies, rechazar cookies de terceros o solo aceptar cookies de origen, y aceptar cookies siempre. A ello habría que añadir requisito de información proporcionando al usuario la información pertinente sobre los riesgos que puede entrañar autorizar el almacenamiento de cookies de terceros en el ordenador ${ }^{124}$ (incluyendo la conservación a largo plazo de registros de los historiales de navegación y el uso de los mismos para enviar publicidad comportamental). Esto impediría disuadirle de seleccionar una configuración de privacidad menor y podría contribuir a establecer un mayor equilibrio entre la privacidad del usuario y los derechos del sector de la industria. Si bien no nos encontramos ante una configuración por defecto, si podemos decir que se está solicitando al usuario a optar por una de tres configuraciones establecidas por defecto.

123 European Data Protection Supervisor recommendations on specific aspects of the proposed ePrivacy Regulation, 5 October 2017, pág. 2.

124 Vid. CDO 24 de la Propuesta ePrivacy Regulation. 


\section{EL CONSENTIMINETO PARA COOKIES EN LA PROPUESTA ePRIVACY REGULATION.}

La Propuesta ePrivacy Regulation establece el consentimiento como principio para determinar la protección de la información almacenada en los equipos terminales que es obtenida a través de cookies y utilizada con fines de publicidad comportamental. Por el contrario, se establece una prohibición general del uso de esa información y una serie de excepciones. Las excepciones a), c), y d) del art. 8.1 son claras ya que se refieren a cookies necesarios que no suponen un riesgo para la privacidad del usuario. En estos casos no es necesario solicitar el consentimiento del usuario final. Por el contrario, la excepción del apartado b) se refiere a la necesidad de que el usuario final dé su consentimiento para la instalación de cookies que no son necesarios y que por tanto pueden entrañar un riesgo para su privacidad. El usuario deberá decidir los riesgos que está dispuesto a asumir. La regulación de esta excepción se basa por tanto en un sistema opt-in, pero únicamente esta excepción. La Propuesta ePrivacy Regulation en su art. 1 ya indica que sus disposiciones precisan y complementan las del RGPD estableciendo normas específicas en el ámbito de la prestación y utilización de servicios de comunicaciones electrónicas y, en particular, los derechos al respeto de la vida privada y las comunicaciones y la protección de las personas físicas en lo que respecta al tratamiento de datos personales. Al remitir a la definición del consentimiento dada en el RGPD, cuando se aplique la excepción se deberán cumplir todos los requisitos contenidos en su definición para que se considere válido.

La excepción a la prohibición general que permite la instalación de cookies a través del consentimiento del usuario regulada a través del art. $8.1 \mathrm{~b}$ ) establece dos posibles mecanismos a través de los que el usuario puede prestar su consentimiento. El consentimiento se podrá expresar como ya se ha visto mediante la configuración de las opciones de privacidad de las aplicaciones "cuando sea técnicamente posible y factible", pero ello no es óbice para que los operadores de las páginas web continúen mostrando sus avisos de cookies o declaraciones de aceptación. La posibilidad de articular el sistema opt-in a través de dos mecanismos diferentes nos parece, cuanto menos complicada desde un punto de vista práctico pues estamos seguros que si se mantiene la redacción actual, tras la entrada en vigor del futuro ePrivacy Regulation convivirán ambos sistemas. Creemos también que las declaraciones de aceptación alojadas en páginas web que cumplen la normativa vigente seguirán siendo conforme a derecho. De la redacción cuando haya dado su consentimiento queda 
claro que se mantienen el requisito de que el consentimiento se preste de forma previa a la instalación de cookies. La aplicación del art. 7 del RGPD mantendrá las condiciones actuales para el consentimiento y con ello la necesidad de que las declaraciones se presenten de forma que se distingan claramente de los demás asuntos sean inteligibles y de fácil acceso y utilicen lenguaje claro y sencillo. Además las declaraciones deberán seguir incluyendo información que indique cómo retirar el consentimiento y para que el consentimiento se considere libre no se podrá supeditar el consentimiento del tratamiento de datos que no son necesarios para la prestación de un servicio o la ejecución de un contrato.

Debemos sin embargo, manifestar ciertas reservas en cuanto al cumplimiento de las condiciones del consentimiento por parte de las configuraciones de los programas. Éstas se refieren, a la existencia o no de una configuración por defecto del programa previa a la instalación, a las diferentes opciones de configuración previas a la instalación y, a la posibilidad de realizar cambios en la configuración de los parámetros de privacidad una vez instalado el programa. El art. 10 establece que se ofrecerá la posibilidad de impedir a terceros almacenar información sobre el equipo terminal de un usuario final o el tratamiento de información ya almacenada en ese equipo. Esta posibilidad ha de materializarse al iniciarse la instalación del programa en cuestión, solicitando al usuario que preste su consentimiento respecto de una configuración determinada. A su vez, el CDO 24 establece que la información proporcionada no ha de disuadir a los usuarios finales de seleccionar una configuración de mayor privacidad. La interpretación conjunta de ambos hace pensar que no se establece una configuración por defecto sino por opción ${ }^{125}$. Como ya es sabido, la mayoría de los navegadores están configurados por defecto para aceptar todos los cookies tal y como advierte el CDO 23 de la Propuesta ePrivacy Regulation. Las declaraciones que contienen casillas que ya están marcadas por defecto para aceptar los cookies de publicidad comportamental ya se ha dicho no son expresión de voluntad libre ni constituyen una acción clara. Por analogía, es evidente que los buscadores configurados de este modo, no resultarían un instrumento válido para otorgar el consentimiento. A efectos de establecer una mayor protección de la privacidad, la casilla de la configuración correspondiente a "rechazar todos los cookies" debería estar marcada por defecto en línea conforme a lo establecido en art. 25

125 GASCÓN MARCÉN, A., "El Reglamento sobre la privacidad y las comunicaciones electrónicas, la asignatura pendiente del Mercado Único Digital." Madrid: CEU Ediciones, 2020, pág. 19. 
del RGPD ${ }^{126}$. Pese a que el GT29 ya indicó que únicamente cuando el buscador esté configurado por defecto para rechazar todos los cookies y el usuario cambie esta configuración para aceptarlos explícitamente se considerará válido el consentimiento ${ }^{127}$, y a las recomendaciones del SEPD ${ }^{128}$ todo indica que no estamos ante este supuesto.

Efectivamente, los usuarios estarían más protegidos cuando hiciesen caso omiso de la información o cuando ésta no cumpliese los requisitos de claridad y sencillez. Así la imposición del nivel más elevado de protección operaría cuando no se pudiera garantizar que la declaración de voluntad corresponde a una decisión informada. No nos engañemos, muchos usuarios simplemente prestan su consentimiento dando por válido aquello marcado por defecto sin prestar atención a la información o cuando ésta no es clara o sencilla. Una configuración por opción en la que ninguna casilla estuviera marcada por defecto, y que impediría proseguir con la instalación del programa y obligaría al usuario a detenerse. Sin embargo, nada garantiza que el usuario marque una casilla cualquiera sin leer la información correspondiente, aunque se presuma que sí lo ha hecho. Por tanto, la configuración por opción ofrece menores garantías de privacidad que si se estableciera por defecto. Por lo que respecta al requisito de que exista una acción clara y positiva, tanto si el usuario cambia una configuración la marcada por defecto (que otorga un mayor nivel de protección) por otra configuración, como si marca una casilla cuando ninguna está seleccionada entendemos que se está dando cumplimiento a la necesidad de realizar una acción clara y mostrar así un comportamiento activo.

La configuración del nivel de privacidad antes de la instalación del programa es otro punto a destacar. Al interpretar el artículo 10.2 que indica que se solicitará el consentimiento del usuario final re-

126 Recordemos que el artículo 25 del RGPD establece que se tomarán medidas técnicas y organizativas garantizarán en particular que, por defecto, los datos personales no sean accesibles, sin la intervención de la persona, a un número indeterminado de personas físicas. Estas medidas están destinadas a que sólo sean objeto de tratamiento los datos personales que sean necesarios para cada uno de los fines específicos del tratamiento. Se aplicará esta obligación a la cantidad de datos personales recogidos, a la extensión de su tratamiento, a su plazo de conservación y a su accesibilidad.

127 Dictamen 2/2010, apartado 6.4, pág. 26.

128 El SEPD recomienda que la propuesta del reglamento sobre privacidad imponga a los proveedores de hardware y software la obligación de implementar configuraciones por defecto que protejan los dispositivos de los usuarios frente a cualquier accedo o almacenamiento no autorizado. Supervisor Europeo de Protección de Datos (2017). Opinion 6/2017 on the Proposal for a Regulation on Privacy and Electronic Communications (ePrivacy Regulation), págs. 18-19. 
specto de una configuración determinada, se desprende la posibilidad de elegir entre diferentes niveles de privacidad o protección. En primer lugar, porque el CDO 23 indica la conveniencia de que los proveedores de estos programas, como por ejemplo los navegadores, estén obligados a ofrecer la posibilidad de impedir a terceros almacenar información y en segundo porque también indica que los usuarios han de disponer de una serie de opciones de configuración correspondientes a diferentes niveles de privacidad. Sin embargo, entendemos que se refiere a configuraciones ya establecidas puesto que se proponen tres: no aceptar nunca cookies (nivel elevado de privacidad) ${ }^{129}$, rechazar cookies de terceros o sólo aceptar cookies de origen (nivel intermedio), y aceptar cookies siempre (nivel más bajo). Recordemos que la definición del consentimiento requiere que éste sea específico refiriéndose a los fines del tratamiento. Por ello el establecimiento de únicamente una configuración de nivel intermedio podría implicar que el consentimiento no fuera específico puesto que los cookies de origen también pueden utilizarse con fines de publicidad comportamental ${ }^{130}$. Recordemos también que los paquetes de consentimiento no se consideran válidos, y que cuando el tratamiento de datos tiene varios fines debe solicitarse el consentimiento para todos ellos ${ }^{131}$. Por ello consideramos que el consentimiento únicamente se consideraría válido si las opciones de configuración de privacidad de nivel intermedio incluyesen los diferentes fines del tratamiento. A su vez para dar cumplimiento al deber de información, los ajustes de privacidad han de presentarse de forma bien visible e inteligible ${ }^{132}$, y la información que contengan no debe disuadir al usuario de elegir una configuración que otorgue una mayor protección, y por tanto debe incluir la información pertinente sobre los riesgos que puede entrañar autorizar el almacenamiento de cookies de ter$\operatorname{ceros}^{133}$, dando cumplimiento al deber de información.

Finalmente, la posibilidad de realizar cambios posteriores a la instalación en la configuración no está prevista en el articulado de

129 Se entiende que no se rechazaran los cookies que estén exentos conforme al artículo 8.1 a), c), y d) de la Propuesta RP.

130 Recordemos también que los cookies de origen también pueden utilizarse con fines de publicidad comportamental conforme al Dictamen 2/2010, pág. 6.

131 Vid. CDO 32 del RGPD.

132 Vid. CDO 23 Propuesta ePrivacy Regulation.

133 El CDO 24 de la Propuesta RP establece que La información proporcionada no ha de disuadir a los usuarios finales de seleccionar una configuración de mayor privacidad y debe incluir la información pertinente sobre los riesgos que puede entrañar autorizar el almacenamiento de cookies de terceros en el ordenador, incluyendo la conservación a largo plazo de registros de los historiales de navegación y el uso de los mismos para enviar publicidad personalizada. 
la Propuesta ePrivacy Regulation. El CDO 24 la anuncia indicando la conveniencia de que los navegadores propongan métodos sencillos para modificar la configuración de privacidad en cualquier momento durante la utilización. Se incluye que les permita excluir o aceptar determinados sitios web o especificar en qué sitios web se aceptan siempre o no aceptan nunca cookies. Creemos conveniente que se incluya un nuevo apartado en el artículo 10 ya que esta modificación permitiría, en consonancia con la propuesta del EDPS que el usuario retirase su consentimiento ${ }^{134}$ en cualquier momento o estableciera configuraciones específicas. Esta modificación posibilitaría también la correcta aplicación del artículo 9.1 de la Propuesta ePrivacy Regulation que indica que serán aplicables las condiciones relativas al consentimiento establecidas en el art. 7 RGPD, en concreto su apartado tercero que indica que el interesado tendrá derecho a retirar su consentimiento en cualquier momento.

\section{VIII.A. Refuerzo moderado de la privacidad.}

Nos preguntamos si la regulación de la instalación de cookies potencialmente "intrusivos" a través del consentimiento de los usuarios que viene a futuro será capaz de proteger la privacidad en la misma, o en mayor medida. No sólo porque la regla sobre cookies vigente basada en las declaraciones o avisos de cookies no ha alcanzado los niveles de eficacia deseados, sino porque la configuración por opción de los programas como los navegadores creemos que no impedirá en muchos casos que los cookies de las páginas web se sigan instalando en los terminales sin que los usuarios tengan plena conciencia de las consecuencias. Consideramos además que la configuración por opción no es consistente con el artículo 25 del RGPD y debería establecerse una configuración por defecto para rechazar todos los cookies.

Si finalmente se determina una configuración por opción, en el caso de que el usuario eligiera la opción de rechazar todos los cookies, si bien estaría más protegido, ello podría evitar que tuviera acceso a determinados contenidos y servicios. Dado que en la actualidad hay páginas web que impiden este acceso si los usuarios

134 El SEPD propone que la posibilidad de retirar el consentimiento establecida en el artículo 9.3 se haga extensible al artículo 8.1 b) en lugar de crear un apartado en el artículo $1^{\circ}$ que prevea esta posibilidad así com ola de realizar otros cambios en las configuraciones de privacidad. Supervisor Europeo de Protección de Datos (2017). Opinion 6/2017 on the Proposal for a Regulationon Privacy and Electronic Communications (ePrivacy Regulation), pág. 30.

(C) UNED. Revista de Derecho UNED, núm. 27, 2021 
se niegan a aceptar todos los cookies, los ya mencionados "cookie walls" entendemos que igualmente se negará el acceso cuando el navegador esté configurado para rechazarlos. En el contexto de la ejecución de un contrato, incluida la prestación de un servicio, supeditar el consentimiento al tratamiento de datos personales que no son necesarios para la ejecución de dicho contrato supone que el consentimiento no se presta libremente y por tanto no es válido conforme al artículo 7.4 RGPD. Sin embargo esta práctica puede resultar lógica desde la óptica del dueño de la página web, que no ve el motivo por el que debería permitir el acceso a sus contenidos o servicios sin recibir una contraprestación. El problema radica en que se estaría exigiendo que los usuarios entreguen sus datos personales, y no se les da otras opciones para acceder, generándose un desequilibrio entre el prestador de servicios y el usuario. La Comisión, haciéndose eco de las críticas recibidas en torno a esta práctica preguntaba en la consulta realizada en $2015^{135}$, la conveniencia de establecer una de las siguientes posibles soluciones: en primer lugar si los servicios de la sociedad de la información deberían cobrar a cambio de no proporcionar publicidad comportamental, y en segundo, si los proveedores de servicios no deberían tener derecho a negar el acceso a sus servicios cuando no fuesen de suscripción y los cookies utilizados no fueran necesarios para acceder al servicio. Las diferentes opiniones recogidas en la evaluación Ex-post REFIT de la Directiva 2002/58/CE indican que los ciudadanos, consumidores y las organizaciones de la sociedad civil apoyan mayoritariamente la primera opción mientras que el sector de la industria está claramente en contra de ambas opciones. La postura de este sector no carece de lógica puesto que sustituir la publicidad comportamental por el pago de un canon para acceder al servicio discriminaría entre usuarios con diferente poder adquisitivo, no sería comercialmente viable para muchas empresas en línea y sería contrario al derecho

135 Annex II: Stakeholder Consultation on the evaluation and review of the ePrivacy Directive: A Eurostat community survey on ICT usage by households and individuals of December 2015, (specific questions on citizens' level of awareness of cookie tracking) 19; A public consultation on the evaluation and review of the ePrivacy Directive (open from 12 April - 5 July 2016); A Eurobarometer survey on e-Privacy, targeting citizens (conducted in July 2016).

La consulta realizada a las partes interesadas estaba compuesta por tres encuestas y forma parte del documento (sólo disponible en inglés): COMMISSION STAFF WORKING DOCUMENT Ex-post REFIT evaluation of the ePrivacy Directive 2002/58/EC. Accompanying the document Proposal for a Regulation of the European Parliament and the Council on the protection of privacy and confidentiality in relation to electronic communications and repealing Directive 2002/58/EC (Regulation on Privacy and Electronic Communications) Brussels, 10.1.2017 SWD(2017) 5 final, pág. 79. 
fundamental de empresa ${ }^{136}$. Además, aquéllos en contra de la opción de no negar el acceso a los servicios en caso de que no se acepten los cookies, arguyen que la ley no debería imponer un modelo de negocio concreto y que los anuncios basados en publicidad comportamental, posibles gracias a los cookies, son una forma de asegurar la viabilidad del negocio. Si bien, el CEPD es claro en este aspecto al indicar que el proveedor de servicios no puede impedir a los usuarios el acceso al servicio cuando no presten su consentimiento ${ }^{137}$ no debemos olvidar que sus opiniones no son vinculantes y que se refieren a la legislación vigente. Por tanto, las dudas de la Comisión están completamente justificadas, pues no se puede garantizar que las autoridades de protección de datos de todos los EEMMs interpreten la norma de la misma manera. Quizá por ello, el SEPD, que opina que las paredes de cookies no deben ser permitidas, manifiesta que la Propuesta ePrivacy Regulation es poco ambiciosa en este respecto y hace un llamamiento al legislador a que asegure que el consentimiento en estos casos se otorgue libremente ${ }^{138}$.

No cabe duda que establecer un equilibrio entre los intereses de los prestadores de servicios y la protección de la privacidad de los potenciales consumidores es una tarea pendiente. Los primeros pueden ver en una posible configuración por defecto una clara amenaza a sus beneficios potenciales lo que se podría traducir en un aumento en los precios, máxime si se impusiera la obligación de no negar el acceso a los contenidos. La información o datos personales, descritos como "la materia prima" de los modelos de negocio digitales, se han convertido en un factor de competitividad para las empresas cuando son utilizados entre otros para la elaboración de publicidad comportamental ${ }^{139}$. En definitiva, la finalidad de los cookies de publicidad comportamental no es otra que el enriquecimiento de las empresas. Al solicitar el consentimiento para colectar nuestros datos en muchas ocasiones no sólo persiguen mejorar sus ventas a través de la publicidad comportamental, sino también obtener beneficios a través de "socios" cuando éstos colectan datos a través de

136 Artículo 16 de la Carta de los Derechos Fundamentales de la Unión Europea. DO C 326 de 26.10.2012, págs. 391-407.

137 Vid. Directrices 05/2020. El elemento de la manifestación libre está vinculado al condicionamiento de la voluntad, la disociación de las finalidades del tratamiento y a los posibles perjuicios de la manifestación de la voluntad. Para otros ejemplos en los que el consentimiento no se considera válidamente otorgado, págs. 11-12.

138 Opinion 6/2017 on the Proposal for a Regulation on Privacy and Electronic Communications (ePrivacy Regulation), pág. 23.

139 Monopolkomission report, 'Competition policy: The challenge of digital markets', 2015, pág. 36.

https://www.monopolkommission.de/images/PDF/SG/s68_fulltext_eng.pdf

(C) UNED. Revista de Derecho UNED, núm. 27, 2021 
cookies de terceros. Es importante resaltar que cuanto mayor sea la red publicitaria, mayores recursos para controlar a los usuarios y rastrear su comportamiento ${ }^{140}$, y más detallados serán los perfiles resultantes del tratamiento de los datos.

El miedo ante la posibilidad de que estos perfiles basados en los hábitos de navegación puedan incluir no sólo los hábitos de compra, sino también preferencias relativas a orientaciones políticas religiosas o sexuales ${ }^{141}$ es otro motivo por el que la regulación de la exención de cookies a través del consentimiento del usuario debería ser objeto del mayor grado de protección posible creemos exige reforzar el sistema de protección y establecer una configuración de privacidad por defecto pese a las consecuencias que pueda tener para los prestadores de servicios. Una vez se ha prestado el consentimiento resulta difícil escapar a este control porque en mayor o menor medida, todos nos vemos inmersos y vinculados al tratamiento automatizado de nuestros datos ${ }^{142}$. Establecer el pago por parte de los usuarios para acceder a servicios y contenidos no nos parece descabellado pues los prestadores de servicios han de obtener una contraprestación, pero ésta creemos no debe consistir en los datos personales.

La redacción de la Propuesta ePrivacy Regulation establece por todo ello refuerzo moderado de la privacidad ${ }^{143}$ del usuario lo que implica que cuando los usuarios presten su consentimiento han de ser conscientes no sólo de que están cediendo sus datos sino también de los peligros los que se exponen como evidencian las noticias en prensa. El "mercadeo" 144 de datos entre socios, como ha sido el escándalo de Facebook es un ejemplo de ello. Éste culminó con la imposición de una multa millonaria por parte de la Federal Trade Commission a Facebook, y puso de manifiesto la violación de la pri-

140 GARRIGA DOMÍNGUEZ, A. Nuevos retos para la protección de datos personales. En la Era del Big Data y de la computación ubicua, 2016, Dykinson, pág. 43.

${ }^{141}$ Monopolkomission report, 'Competition policy: The challenge of digital markets', 2015, pág. 33.

https://www.monopolkommission.de/images/PDF/SG/s68_fulltext_eng.pdf

142 CAMPUZANO TOMÉ, E., Vida privada y datos personales. 2000, Tecnos, pág. 58. En, Garriga Domínguez, A. Nuevos retos para la protección de datos personales. En la Era del Big Data y de la computación ubicua. (2016). Dykinson, pág. 43.

${ }_{143}$ Propuesta de Reglamento del Parlamento Europeo y del Consejo sobre el respeto de la vida privada y la protección de los datos personales en el sector de las comunicaciones electrónicas y por el que se deroga la Directiva 2002/58/CE (Reglamento sobre la privacidad y las comunicaciones electrónicas). Bruselas, 10.1.2017.

$\operatorname{COM}(2017) 10$ final 2017/0003 (COD). Exposición de motivos, pág. 8.

144 CONTRERAS, M., "Así es como las grandes empresas venden tus datos en internet”, El Confidencial, 14/09/2015 05:00, https://www.elconfidencial.com/tecnologia/2015-09-14/asi-es-como-venden-tus-datos-personales-en-internet_1011071/ 
vacidad de sus usuarios y malas prácticas en la gestión de de la seguridad de sus datos al compartidos con Cambridge Analytics ${ }^{145}$. También se producen filtraciones de datos como es el caso Celebgate en el que mediante técnicas de "phishing" se robaron todo tipo de datos de cuentas de Apple y se filtraron fotografías de celebridades $^{146}$ o el caso de vulnerabilidades en Google+ que permitía el acceso a datos personales de los usuarios registrados ${ }^{147}$. La venta ilegal de bases de datos en la "dark web" o la web oscura ${ }^{148}$ también son objeto de noticias, e incluso hay empresas que se dedican a compran bases de datos personales a las aplicaciones y servicios digitales que extraen información de sus usuarios, las cruzan con otras, extrapolan conclusiones sobre qué quiere consumir cada persona en cada momento y venden el resultado a las empresas para que les muestren sus anuncios $^{149}$.

Los usuarios tendrán que actuar con responsabilidad al configurar los parámetros de seguridad de los navegadores, lo que exigirá abordar una tarea de educación de la ciudadanía. Si las páginas web supeditan el acceso a sus contenidos a la instalación de cookies y no se implementan formas alternativas que permitan el acceso a los contenidos o a los servicios como la propuesta por la Comisión, los usuarios tendrán que entender que para acceder a un sitio gratuito tendrán que dar algo a cambio, en concreto sus datos personales, y aceptar tanto que terceros estén en posesión de perfiles respecto a

145 "Cambridge Analytica: la multa récord que deberá pagar Facebook por la forma en que manejó los datos de 87 millones de usuarios", Redacción BBC News Mundo, 24 de Julio 2019,

https://www.bbc.com/mundo/noticias-49093124

146 OHLHEISER, A., "The Shockingly simple way the nude photos of Celebgate were stolen", The Washington Post, 24 de mayo 2016. https://www.washingtonpost. $\mathrm{com} /$ news/the-intersect/wp/2016/03/16/the-shockingly-simple-way-the-nude-photosof-celebgate-were-stolen/

147 Desde el verano de 2015 hasta marzo de 2018, los datos de medio millón de usuarios estuvieron a disposición de cualquier por causa de una vulnerabilidad. Más de dos años después, Google la identificó y subsanó, sin evidencias de que alguien hubiese accedido a la información... ni la certeza absoluta de que no hubiese ocurrido. CASTILLO, J.C., "Las filtraciones de datos más sonadas de las grandes compañías tecnológicas”, El Correo, Jueves, 14 noviembre 2019, 14:58h.

https://www.elcorreo.com/tecnologia/empresas/mayores-filtraciones-datos-20191113113502-nt.html

148 JANSEN, D., "Compraventa de datos personales", Digitalbiz magazine, 5 de noviembre 2019, https://www.digitalbizmagazine.com/compraventa-de-datospersonales/

149 DEL CASTILLO, C., "Así trabaja una empresa española que compra y vende datos personales para hacer publicidad: "Recogemos toda la información posible", El Diario, 21 de octubre de 2019, 22:04h. https://www.eldiario.es/tecnologia/trabajaempresa-compra-venta-personales-sentido_1_1297691.html 
sus gustos y preferencias como los riesgos derivados de accesos no autorizados a sus datos o a sus perfiles.

\section{CONCLUSIONES}

1. La publicidad comportamental en línea surge como consecuencia de los avances tecnológicos que posibilitan rastrear el comportamiento del usuario en internet a través de la instalación de cookies en sus terminales. Éstos acceden y recaban datos alojados en sus terminales que, una vez tratados, suponen la elaboración de perfiles que permiten inferir sus gustos y preferencias y por lo tanto servirles publicidad a medida. A su vez, la obtención de los datos por cuanto componen tales perfiles, puede suponer una injerencia en la esfera privada del individuo, lo que ha generado la necesidad de regular la instalación de cookies en los terminales de los usuarios.

2. La "norma de cookies" se ha caracterizado por ser una regulación móvil pues la convergencia tecnológica, y sus efectos en los sectores del mercado digital ha propiciado sucesivas reformas en un intento por equilibrar la protección de la privacidad de los ciudadanos y los intereses de las empresas que operan en el entorno de internet.

3. El establecimiento inicial por parte del art. 5.3 de la Directiva 2002/58/CE a través del sistema opt-out no cumplió los objetivos planteados. La instalación de cookies era automática y únicamente sometida al deber de información y al derecho de oposición si bien éste último solo podía ejercerse en un momento posterior a la recopilación de los datos.

4. El cambio al sistema opt-in introducido por la modificación del art. 5.3 de la Directiva 2009/136/CE basado en el consentimiento del usuario claramente reforzó el sistema de protección al remitir a la definición dada en la normativa sobre protección de datos. Además, puesto que los cookies de publicidad comportamental recaban datos considerados personales ya que ser tratados para la elaboración de perfiles, el RGPD también resulta de aplicación.

5. A pesar de haber sido reforzado, el régimen actual por el que se regulan los cookies no resulta suficiente. La interpretación de 
la norma por parte de los EEMMs ha supuesto de facto una aplicación heterogénea en el territorio de la Unión que se ha traducido en la creación y proliferación de diferentes avisos de cookies que responden bien a mecanismos de aceptación previos consistentes con un sistema opt-in, bien a mecanismos basados en la configuración de los navegadores que a nuestro parecer se acercan más a la definición de un sistema opt-out.

6. En muchos casos ninguno de los dos mecanismos cumple enteramente la normativa. Pese a las recomendaciones expresadas por el GT29 en sus dictámenes y por el CEPD en sus directrices, algunos mecanismos no permiten la obtención del consentimiento del usuario de forma válida. Tal y como se desprende de la jurisprudencia en los asuntos C-673/17 Planet49 y C-40/17 Fashion ID, así como de la revisión de la Directiva 2002/58/CE llevada a cabo por la Comisión, la "norma de cookies" no resulta enteramente efectiva al poner en evidencia la existencia de casos de incumplimiento.

7. La Comisión, ha presentado una Propuesta de Reglamento sobre privacidad de las comunicaciones electrónicas, la Propuesta ePrivacy Regulation, que en un futuro derogará la Directiva 2002/58/CE con el objetivo de garantizar tanto la coherencia con el RGPD, como ofrecer seguridad jurídica al impedir interpretaciones divergentes en los EEMMs. Nosotros nos atrevemos a decir que la Propuesta ePrivacy Regulation tampoco aportará una solución definitiva pues supone un refuerzo moderado de la privacidad del usuario.

8. La Propuesta ePrivacy Regulation anuncia cambios en la "norma de cookies" que pasan a ser regulados en el art. 8.1. Se establece una prohibición general para acceder y tratar los datos almacenados en los terminales de los usuarios y cuatro excepciones. Tres de ellas obedecen a cookies necesarios para la prestación de un servicio o que no entrañan riesgos, por lo que éstos se instalan automáticamente resultando irrelevante el consentimiento del usuario. La cuarta excepción es la referida a cookies de publicidad comportamental y tecnologías análogas. Si bien se mantiene el sistema opt-in por cuanto el acceso a la información queda supeditado al otorgamiento del consentimiento por parte del usuario, éste se podrá otorgar por dos vías: a través de la configuración de los parámetros de privacidad de los programas que instale (como los navegadores) ó, a 
través de avisos de cookies que constituyan mecanismos de aceptación previa.

9. La Propuesta ePrivacy Regulation da prioridad a la primera opción lo cual supone un cambio frente al sistema anterior. Es más, no impone la obligación de que en los programas se establezca una configuración por defecto ni que ésta corresponda al nivel más elevado de protección de la privacidad, como creemos sería deseable en línea con el art. 25 del RGPD, sino una configuración por opción.

10. Asimismo, creemos necesario que se imponga que los programas incluyan mecanismos que permitan al usuario cambiar los parámetros de privacidad, incluyendo la posibilidad de autorizar o prohibir la instalación de cookies para sitios web concretos, en cualquier momento tal para garantizar que el usuario retenga el control sobre sus elecciones, si bien la conveniencia de incluir estos mecanismos únicamente se apunta en el CDO 24 de la Propuesta ePrivacy Regulation.

11. Ante esta situación, la eficacia del sistema propuesto dependerá, tanto de los conocimientos informáticos y sobre cookies que tenga el usuario, como del diseño que presenten los programas al solicitar que se elija una configuración de privacidad entre varias. Resulta necesario desarrollar la competencia digital de los ciudadanos a través de la educación pues cuando la información proporcionada en la solicitud del consentimiento, no sea clara, sencilla, y comprensible para el ciudadano medio, se correrá el riesgo de que una vez, más por agotamiento, impaciencia, desconocimiento o incluso frustración, elija una configuración a ciegas.

12. Prácticas como las paredes de cookies o "cookie walls" que en opinión del CEPD y el SEPD no deben ser permitidas, podrán impedir que el usuario acceda a los contenidos y servicios de páginas web cuando haya optado por rechazar todos los cookies publicitarios. Alternativas a estas prácticas como sustituir la cesión de datos personales por el pago de un precio en contraprestación al acceso a los contenidos y servicios disponibles en páginas web, no cuenta con el apoyo de los proveedores de servicios, pues ven una disminución potencial de sus beneficios, tanto los generados por la cesión de los datos a terceros como los derivados de la publicidad comportamental. 
13. Estamos ante un primer paso hacia la regulación del nuevo mundo Digital en el que los cookies convivirán con el Internet de las cosas y las OTTs, un nuevo escenario que incluirá también otras tecnologías de rastreo cuyos datos se pueden combinar con los obtenidos a través de los cookies y servir de publicidad comportamental, por lo que tras la aprobación del futuro ePrivacy Regulation será necesario evaluar si la configuración por opción de los parámetros de privacidad de los programas o aplicaciones, resultará suficiente para garantizar el nivel de protección deseable.

14. Nosotros nos atrevemos a sostener que no, y somos de la opinión que el articulado de la Propuesta ePrivacy Regulation debería incluir la configuración por defecto del nivel de privacidad más alto y la posibilidad de modificar los parámetros de privacidad en cualquier momento posterior a la instalación o actualización de los programas para minimizar el acceso a la información de los terminales de los usuarios en un intento por alcanzar un nivel de protección más deseable. La Unión Europea tendrá que estar vigilante y supervisar la implementación del Reglamento en los nuevos escenarios digitales para poder adoptar las medidas y recomendaciones necesarias tendentes a garantizar que no se genere un mayor desequilibrio entre los intereses de las empresas y la protección del derecho a la privacidad de los ciudadanos. 
